Prepared in cooperation with the U.S. Nuclear Regulatory Commission

\title{
Ground-Motion Predictions for California-Comparisons of Three Prediction Equations
}

Open-File Report 2020-1028 



\section{Ground-Motion Predictions for California- Comparisons of Three Prediction Equations}

By Erol Kalkan and Vladimir Graizer

Prepared in cooperation with the U.S. Nuclear Regulatory Commission

Open-File Report 2020-1028 


\title{
U.S. Department of the Interior DAVID BERNHARDT, Secretary
}

\author{
U.S. Geological Survey \\ James F. Reilly II, Director
}

U.S. Geological Survey, Reston, Virginia: 2020

For more information on the USGS - the Federal source for science about the Earth, its natural and living resources, natural hazards, and the environment—visit https://www.usgs.gov or call 1-888-ASK-USGS (1-888-275-8747).

For an overview of USGS information products, including maps, imagery, and publications, visit https://store.usgs.gov.

Any use of trade, firm, or product names is for descriptive purposes only and does not imply endorsement by the U.S. Government.

Although this information product, for the most part, is in the public domain, it also may contain copyrighted materials as noted in the text. Permission to reproduce copyrighted items must be secured from the copyright owner.

Suggested citation:

Kalkan, E., and Graizer, V., 2020, Ground-motion predictions for California-Comparisons of three prediction equations: U.S. Geological Survey Open-File Report 2020-1028, 28 p., https://doi.org/10.3133/ofr20201028.

ISSN 2331-1258 (online) 


\section{Acknowledgments}

The authors would like to thank Emel Seyhan (Risk Management Solutions) and Dan McNamara (U.S. Geological Survey [USGS]) for their reviews, which helped improve the technical quality and presentation of this study. We also thank Annemarie Baltay (USGS) for providing MATLAB functions of the NGA-West2 ground-motion prediction equations.

\section{Contents}

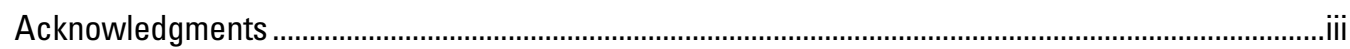

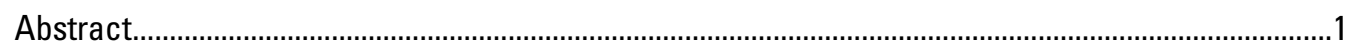

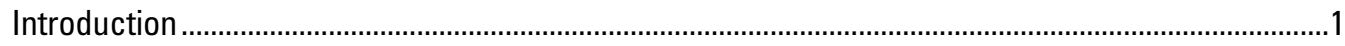

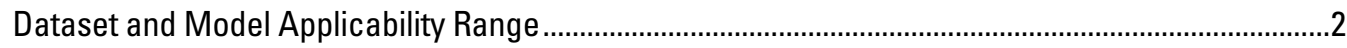

Functional Forms and Parameters of GMPEs ......................................................................................2

Stage 1: Comparisons of Median Predictions ..........................................................................................5

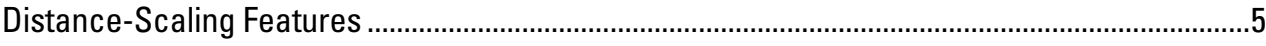

Magnitude-Scaling Features..............................................................................................

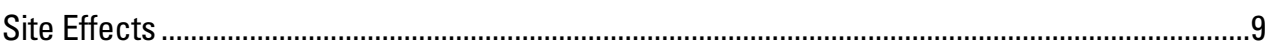

Style-of-Faulting Effects .................................................................................................................

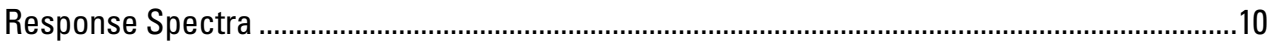

Standard Deviations.........................................................................................................................12

Stage 2: Comparisons with Earthquake Data ......................................................................................12

Stage 3: Comparisons of Residuals Using the NGA-West2 Database ..................................................18

Intra-Event Residuals Analysis of Path, Site, and Basin-Depth Effects ......................................20

Analysis of Source Effects Using Inter-Event Residuals ..............................................................23

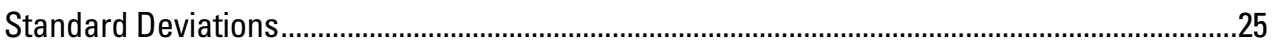

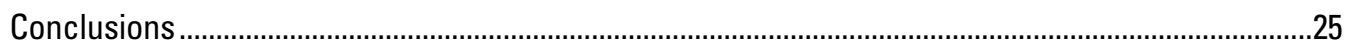

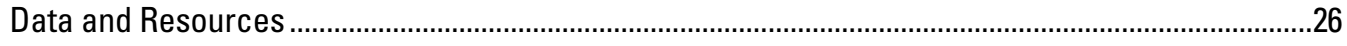

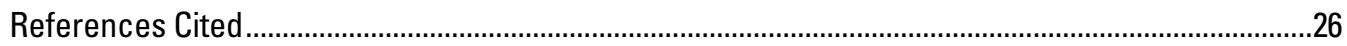




\section{Figures}

1. Plots showing a comparison of distance-scaling features of median estimates of peak ground acceleration and spectral accelerations at $0.2,1.0$, and 3.0 seconds predicted by the Graizer and Kalkan $(2015,2016)$ and Abrahamson and others (2014) ground-motion prediction equations for strike-slip moment magnitude $5,6,7$, and 8 earthquakes.

2. Plots showing a comparison of distance-scaling features of median estimates of peak ground acceleration and spectral acceleration at $0.2,1.0$, and 3.0 seconds predicted by the Graizer and Kalkan $(2015,2016)$ and Boore and others $(2014)$ ground-motion prediction equations for strike-slip moment magnitude 5, 6, 7, and 8 earthquakes.

3. Plots showing a comparison of distance-scaling features of median estimates of peak ground acceleration and spectral acceleration at $0.2,1.0$, and 3.0 seconds predicted by the ground-motion prediction equations of Abrahamson and others (2014) and Boore and others (2014) for strike-slip moment magnitude 5, 6, 7, and 8 earthquakes

4. Plots showing a comparison of magnitude scaling features of median estimates of peak ground acceleration and spectral acceleration at $0.2,1.0$, and 3.0 seconds by the groundmotion prediction equations of Graizer and Kalkan $(2015,2016)$, Abrahamson and others (2014), and Boore and others (2014) for 10, 30, and 150 kilometers

5. Plots showing a comparison of $V_{S 30}$-scaling features of the median estimates of peak ground acceleration and spectral acceleration at $0.2,1.0$, and 3.0 seconds by the groundmotion prediction equations of Graizer and Kalkan $(2015,2016)$, Abrahamson and others (2014), and Boore and others (2014) for a magnitude 7 strike-slip earthquake at 10 and 50 kilometers

6. Plots showing a comparison of style-of-faulting ratios versus period between reverse and strike-slip events and between normal and strike-slip events at 30 kilometers among the Graizer and Kalkan $(2015,2016)$, Abrahamson and others (2014), and Boore and others (2014) ground-motion prediction equations.

7. Plots showing a comparison of $V_{\mathrm{S} 30}$-scaling features of the median estimates of responsespectral shapes and amplitudes versus period among the Graizer and Kalkan $(2015,2016)$, Abrahamson and others (2014), and Boore and others (2014) ground-motion prediction equations for a strike-slip magnitude 7 earthquake at 30 kilometers

8. Plots showing a comparison of the median estimates of response-spectral shapes and amplitudes versus period between the Graizer and Kalkan $(2015,2016)$ and Abrahamson and others (2014) ground-motion prediction equations for strike-slip magnitudes 6, 7, and 8 earthquakes at a rupture distance of 1 and 30 kilometers

9. Plots showing a comparison of the median estimates of response-spectral shapes and amplitudes versus period between the Graizer and Kalkan $(2015,2016)$ and Boore and others (2014) ground-motion prediction equations for strike-slip magnitudes 6, 7, and 8 earthquakes at a rupture distance of 1 and 30 kilometers

10. Plots showing a comparison of total, inter-event, and intra-event variability versus period of the Graizer and Kalkan (2015, 2016), Abrahamson and others (2014), and Boore and others (2014) ground-motion prediction equations for a magnitude 5 earthquake.

11. Plots showing a comparison of the median estimates of response-spectral shapes and amplitudes versus period by the Graizer and Kalkan $(2015,2016)$, Abrahamson and others (2014), and Boore and others (2014) ground-motion prediction equations with the observations from select six major Californian earthquakes from the NGA-West2 database 
12. Plots showing a comparison of the median estimates of response-spectral shapes and amplitudes versus period by the Graizer and Kalkan $(2015,2016)$, Abrahamson and others (2014), and Boore and others (2014) ground-motion prediction equations with the observations from select nine major Californian earthquakes from the NGA-West2 database.

13. Plots showing a comparison of the median estimates of response-spectral shapes and amplitudes versus period by the Graizer and Kalkan $(2015,2016)$, Abrahamson and others (2014), and Boore and others (2014) ground-motion prediction equations with the observations from select six major Californian earthquakes from the NGA-West2 database..

14. Plots showing ground-motion attenuation during the 2014 magnitude 6 South Napa earthquake, California

15. Plots showing the distribution of the NGA-West2 near-source California earthquake events with respect to moment magnitude, $V_{\text {S30 }}$ and $R_{\text {rup }}$.

16. Plots showing the distribution of intra-event residuals in natural logarithmic units for peak ground acceleration and spectral acceleration at $0.2,1.0$, and 3.0 seconds with respect to $R_{\text {rup }}$

17. Plots showing the distribution of intra-event residuals in natural logarithmic units for peak ground acceleration and spectral acceleration at $0.2,1.0$, and 3.0 seconds with respect to $V_{\mathrm{S} 30}$

18. Plots showing the distribution of intra-event residuals in natural logarithmic units for peak ground acceleration and spectral acceleration at $0.2,1.0$, and 3.0 seconds with respect to $B_{\text {depth }}$.

19. Plots showing the distribution of event terms in natural logarithmic units for peak ground acceleration and spectral acceleration at $0.2,1.0$, and 3.0 seconds with respect to moment magnitude

20. Plots showing the distribution of event terms in natural logarithmic units for peak ground acceleration and spectral acceleration at $0.2,1.0$, and 3.0 seconds with respect to style-offaulting parameter $F$.

\section{Tables}

1. Earthquakes used to update the Graizer and Kalkan (GK15) ground-motion prediction equation.

2. Summary of databases, intensity measures, and applicability ranges of independent predictors three ground-motion prediction equations.

3. Event terms for the $\mathbf{2 0 1 4}$ magnitude 6.0 South Napa earthquake for three ground-motion prediction equations

4. List of California earthquake events in a near-source subset of the NGA-West2 database... 19

5. Maximum-likelihood fit to intra-event residuals and distance for three ground-motion prediction equations

6. Maximum-likelihood fit to inter-event residuals and moment magnitude for three ground-motion prediction equations.

7. Standard deviations of residuals in natural logarithmic units for three ground-motion prediction equations for near-source California earthquake events 


\section{Abbreviations}

$\begin{array}{ll}\text { ASK14 } & \text { Abrahamson and others (2014) } \\ \text { BSSA14 } & \text { Boore and others (2014) } \\ g & \text { gravitational acceleration } \\ \text { GK15 } & \text { Graizer and Kalkan (2015, 2016) } \\ \text { GM } & \text { ground motion } \\ \text { GMPE } & \text { ground-motion prediction equation } \\ \text { GMRotl50 } & \text { orientation-independent geometric mean ground motion measure } \\ \text { GMRotD50 } & \text { orientation-independent but period-dependent geometric mean ground motion } \\ \text { km } & \text { measure } \\ \text { km/s } & \text { kilometers } \\ \text { M } & \text { kilometers per second } \\ \text { m } & \text { magnitude } \\ \text { m/s } & \text { meters } \\ \text { NEHRP } & \text { meters per second } \\ \text { NGA } & \text { National Earthquake Hazards Reduction Program } \\ \text { NM } & \text { Next Generation Attenuation project } \\ \text { PGA } & \text { normal faulting } \\ \text { PGV } & \text { peak ground acceleration } \\ \text { REV } & \text { peak ground velocity } \\ \text { s } & \text { reverse faulting } \\ \text { SOF } & \text { seconds } \\ \text { SA } & \text { style of faulting } \\ \text { SS } & \text { spectral acceleration } \\ \text { U } & \text { strike slip faulting } \\ \text { unspecified faulting mechanism } \\ \end{array}$




\section{Notation}

a

b

$B_{\text {depth }}$

F

$R_{\mathrm{JB}}$

$R_{\text {rup }}$

$\operatorname{Res}_{\mathrm{ij}}$

$O_{0}$

$v_{\mathrm{S} 30}$

$Z_{1.0}$

$Z_{1.5}$

$\mathrm{Z}_{\mathrm{TOR}}$

$\delta_{21}$

$\sigma$

$\eta_{\mathrm{i}}$

$\varepsilon_{\text {ij }}$

T

$\phi$ intercept of maximum-likelihood fit

slope of maximum-likelihood fit

basin depth

style-of-faulting parameter used in Graizer and Kalkan $(2015,2016)$

closest distance to horizontal projection of fault rupture plane

closest distance to fault rupture

residual of jth recording of ith earthquake

quality factor at 1 hertz

shear-wave velocity in upper 30 meters of geologic profile

depth to $1.0 \mathrm{~km} / \mathrm{s}$ shear-wave velocity isosurface

depth to $1.5 \mathrm{~km} / \mathrm{s}$ shear-wave velocity isosurface

depth to top of rupture plane

depth differential used in BSSA14

total standard deviation

event term for event $\mathrm{i}$

intra-event residual for recording $\mathrm{j}$ in event $\mathrm{i}$

standard deviation of event term

standard deviation of intra-event term 



\title{
Ground-Motion Predictions for California-Comparisons of Three Prediction Equations
}

\author{
By Erol Kalkan' and Vladmir Graizer ${ }^{2}$
}

\begin{abstract}
We systematically evaluate datasets, functional forms, independent parameters of estimation, and resulting groundmotion predictions (as median and aleatory variability) of the Graizer and Kalkan (2015, 2016) (GK15) ground-motion prediction equation (GMPE) with the next generation of attenuation project (NGA-West2) models of Abrahamson and others (2014) (ASK14) and Boore and others (2014) (BSSA14) for application to earthquakes in California. This evaluation is performed in three stages: (1) by comparing attenuation, magnitude scaling, style-of-faulting effects, site response, response-spectral shape and amplitude, and standard deviations; (2) by comparing median predictions, standard deviations, and analyses of residuals with respect to near-field (within 20 kilometers [km] of the fault) and intermediate-field (50 to $70 \mathrm{~km}$ from the fault) records from major earthquakes in California, and (3) by comparing total, intra-event, and inter-event residual distributions among the GMPEs with respect to a near-source (within $80 \mathrm{~km}$ of the fault) subset of the NGA-West 2 database covering 975 ground motions from 73 events in California ranging from moment magnitude 5 to 7.36. The results reveal that the scaling features of the GK15 GMPE and the ASK14 and BSSA14 GMPEs are, in general, similar in terms of distance attenuation but differ in terms of scaling with magnitude, style of faulting, and site effects. The original standard deviations of GMPEs are also different. For the near-source California subset, the three GMPEs result in standard deviations that are similar to each other. The mixedeffect residuals analysis shows that the GK15 GMPE has no perceptible trend with respect to the independent predictors.
\end{abstract}

\section{Introduction}

The previous version of the Graizer and Kalkan (2015, 2016) (herein abbreviated as GK15) ground-motion prediction equation (GMPE) was developed using the NGA-West1 database (Chiou and others, 2008) along with additional records from

${ }^{1}$ QuakeLogic Inc., Roseville, California.

${ }^{2}$ U.S. Nuclear Regulatory Commission. major events in California and several earthquakes from other shallow crustal continental regions (Graizer and Kalkan, 2007, 2009). The NGA-West2 project (Bozorgnia and others, 2014) and recent earthquake data (Baltay and Boatwright, 2015) accentuated a need to include regionalization in GMPEs to account for differences in far-source (beyond 80 kilometers [km]) distance attenuation and soil response. Motivated by this need, we have updated our GMPE to include a new anelastic attenuation term as a function of the quality factor at 1 hertz $\left(Q_{0}\right)$ to capture regional differences in far-source attenuation and a new frequencydependent sedimentary-basin scaling term as a function of depth to the 1.5 kilometer per second $(\mathrm{km} / \mathrm{s})$ shear-wave velocity isosurface to improve ground-motion predictions for sites on deep sedimentary basins (the GK15 GMPE does not explicitly consider strong basin amplification on shallow basins).

In this report, we systematically compare the datasets, functional forms, independent predictor variables, and resulting ground-motion estimates (as median and aleatory variability) of GK15 with the broadly used next generation of attenuation project (NGA-West2) models of Abrahamson and others (2014) (herein abbreviated as ASK14) and Boore and others (2014) (herein abbreviated as BSSA14) for application to earthquakes in California. We do not include three other NGA-West2 modelsCampbell and Bozorgnia (2014), Chiou and Youngs (2014), or Idriss (2014) - for brevity and because they compare well with the ASK14 and BSSA14 GMPEs (Gregor and others, 2014). The evaluation of the GMPEs here is performed in three stages:

1. Compare distance attenuation, magnitude scaling, style-of-faulting (SOF) effects, site response, responsespectral shape and amplitude, and standard deviations;

2. Compare median predictions, standard deviations, and analyses of total residuals with respect to near-field (within $20 \mathrm{~km}$ of the fault) and intermediate-field (50 to $70 \mathrm{~km}$ from the fault) records from major earthquakes in California; and

3. Compare total, intra-event, and inter-event residuals among the GMPEs by using a near-source (within $80 \mathrm{~km}$ of the fault [Campbell, 2016]) subset of the NGA-West2 database.

Results of these comparisons are presented in the following sections. 


\section{Dataset and Model Applicability Range}

In development of the GK15 GMPE, a total of 2,583 ground-motion recordings from 47 shallow crustal continental earthquakes with focal depths less than $20 \mathrm{~km}$ were used. This dataset, summarized in table 1, includes events gathered from the Pacific Earthquake Engineering Research Center database created under the NGA-West1 project (Chiou and others, 2008) and data from several additional events and stations. Specifically, additional data from the following California and international earthquakes were included: 1994 magnitude $(M) 6.7$ Northridge, 1999 M7.1 Hector Mine, 2003 M4.9 Big Bear City, 2003 M6.5 San Simeon, 2004 M6 Parkfield, 2005 M5.2 Anza and M4.9 Yucaipa, 1976 M6.8 Gazli (Uzbekistan), 1988 M6.8 Spitak (Armenia), 1991 M6.2 Racha (Georgia), and 1999 M7.4 Kocaeli and M7.2 Düzce (Turkey). The source for additional data was primarily the Center for Engineering Strong Motion Data. To avoid bias, the records were processed uniformly (that is, the same corner frequencies and n-roll value were used for acausal filtering and the filter corner frequencies were selected conservatively to accommodate a range of signal-to-noise ratio).

A total of 47 earthquakes were selected and can be summarized as follows: 32 earthquakes from California; 6 earthquakes from Turkey; 4 earthquakes from Taiwan and Italy; 3 earthquakes from Armenia, Georgia, and Uzbekistan; and 2 earthquakes from Alaska and Nevada. Approximately 70 percent of the earthquakes are from California. This dataset, representing mainshocks only, includes data recorded within 0.2 to $250 \mathrm{~km}$ of the earthquake faults from events in the magnitude range of 4.9 to 7.9 . GMRotI $50^{1}$ is the intensity measure used in the development of the NGA-West1 database (Boore and others, 2006).

The NGA-West2 database (using GMRotD502) includes 21,336 three-component recordings from 600 shallow crustal earthquakes in the magnitude range of 3 to 7.9 and a rupture distance range of 0.05 to $1,533 \mathrm{~km}$ (Ancheta and others, 2014). For ASK14, 15,750 recordings from 326 earthquakes were used in analyses for peak ground acceleration (PGA); among them 274 earthquakes with 12,044 recordings are from California. For BSSA14, 18,436 recordings from 404 events were used for PGA analyses. We did not use the NGA-West2 database for GK15 because it was not available to us.

Based on the final selected datasets used for the GK15, ASK14, and BSSA14 GMPEs, the models' applicable ranges (in terms of magnitude, distance, $V_{\mathrm{S} 30}$ [shear-wave velocity in upper 30 meters of geologic profile], and spectral periods) are listed in table 2 . Additional details are provided in individual papers that describe the GK15, ASK14, and BSSA14 GMPEs (Boore and others, 2014; Abrahamson and others, 2014; Graizer and Kalkan, 2015, 2016). It should also be noted that GK15 provides the predictions for GMRotI50,

${ }^{1}$ This term refers to the orientation-independent geometric mean groundmotion measure.

${ }^{2}$ This term refers to the orientation-independent but period-dependent geometric mean ground-motion measure. a component definition different from that of the NGA-West2 models. We ignored the difference in definitions of component combination because it may be small and does not affect the results of comparisons (Mak and others, 2017; Van Houtte and others, 2017; Farhadi and others, 2018).

\section{Functional Forms and Parameters of GMPEs}

The functional forms of the ASK14 and BSSA14 GMPEs are significantly different than those of the GK15 GMPE. The ASK14 and BSSA14 GMPEs each consist of a single predictive equation covering both PGA and spectral acceleration (SA); however, the GK15 GMPE is composed of two separate predictive equations. The first equation predicts PGA and the second equation constructs the spectral shape. The term spectral shape refers to the acceleration response spectrum normalized by PGA. The final SA response spectrum is obtained by anchoring the spectral shape to the PGA. In this model, the SA response spectrum is a continuous function of the spectral period, which is explained in detail by Graizer and Kalkan (2009). On the other hand, the ASK14 and BSSA14 GMPEs use a discrete functional form for predicting the response spectral ordinates. The concept of a continuous function assumes cross correlation of spectral ordinates at different periods (Baker and Cornell, 2006; Baker and Jayram, 2008) and de facto eliminates the difference between period intervals by making period intervals infinitesimally short. As a result, spectral ordinates are estimated smoothly and a long list of estimator coefficients for a range of spectral periods is eliminated (Graizer and Kalkan, 2009).

Although ground-motion distance attenuation is a complex process, in our opinion, modeling it should not be very complex. According to the principle of parsimony, given a set of possible explanations, the simplest competing explanation is the most likely to be correct (Thorburn, 1915). In our case, the simplicity refers to striking a balance between consistency of a groundmotion prediction model with the observed earthquake data and the prior degree of belief in a model (Cairns, 2000). According to Jeffreys (1961), the prior degree of belief in a model should be inversely related to the number of parameters. In GK15, simplicity postulates. This is evident in two ways. First, GK15 has only 31 estimator coefficients as compared to 1,008 estimator coefficients in ASK14 and 2,889 coefficients in BSSA14. Second, GK15 has a much simpler mathematical form than the other two GMPEs. Vandekerckhove and others (2015) state that "goodness-of-fit must be balanced against model complexity to avoid overfitting - that is, to avoid building models that well explain the data at hand but fail in out-of-sample predictions." The principle of parsimony forces researchers to abandon complex models that are tweaked to the observed data in favor of simpler models that can generalize to new datasets. To prevent overfitting, we not only avoided complex functions but also stopped adding new parameters when we had a high degree of belief that the residual errors are random rather than containing any further structure. We performed a detailed 
Table 1. Earthquakes used to update the Graizer and Kalkan (GK15) ground-motion prediction equation.

[GK15, Graizer and Kalkan (2015, 2016). These events were also used in the development of the GK07-09 model (Graizer and Kalkan, 2007, 2009). Latitude and longitude in decimal degrees north and east. Mtn., Mountain; km, kilometers]

\begin{tabular}{|c|c|c|c|c|c|c|c|c|c|c|}
\hline \multirow{2}{*}{ No. } & \multirow{2}{*}{ Event } & \multirow{2}{*}{ Date } & \multirow{2}{*}{ Style of faulting } & \multirow{2}{*}{$\begin{array}{c}\text { Moment } \\
\text { magnitude }\end{array}$} & \multirow{2}{*}{$\begin{array}{c}\text { Depth } \\
(\mathbf{k m})\end{array}$} & \multicolumn{2}{|c|}{ Epicenter coordinates } & \multirow{2}{*}{$\begin{array}{c}\text { No. of } \\
\text { data }\end{array}$} & \multicolumn{2}{|c|}{ Distance range $(\mathbf{k m})$} \\
\hline & & & & & & Latitude & Longitude & & Min. & Max. \\
\hline 1 & Adana-Ceyhan (Turkey) & 1998 & Strike slip & 6.3 & 18.0 & 36.850 & 35.550 & 4 & 28.0 & 96.0 \\
\hline 2 & Anza & 2005 & Strike slip & 5.2 & 14.2 & 33.529 & -116.573 & 279 & 4.8 & 197.6 \\
\hline 3 & Big Bear City & 2003 & Strike slip & 4.9 & 6.3 & 34.310 & -116.848 & 178 & 8.6 & 166.7 \\
\hline 4 & Bingol (Turkey) & 2003 & Strike slip & 6.4 & 6.0 & 38.940 & 40.510 & 1 & 6.1 & \\
\hline 5 & Bishop (Round Valley) & 1984 & Strike slip & 5.8 & 9.0 & 37.460 & -118.590 & 1 & 21.9 & \\
\hline 6 & Borrego Mtn. & 1968 & Strike slip & 6.6 & 8.0 & 33.190 & -116.142 & 5 & 45.7 & 222.4 \\
\hline 7 & Chalfant Valley & 1986 & Strike slip & 5.8 & 6.7 & 37.577 & -118.449 & 5 & 6.4 & 24.5 \\
\hline 8 & Chi-Chi (Taiwan) & 1999 & Reverse & 7.6 & 16.0 & 23.860 & 120.800 & 420 & 0.3 & 172.2 \\
\hline 9 & Coalinga-01 & 1983 & Reverse & 6.4 & 4.6 & 36.233 & -120.310 & 46 & 8.4 & 55.8 \\
\hline 10 & Coalinga-05 & 1983 & Reverse & 5.8 & 7.4 & 36.241 & 77.191 & 11 & 4.6 & 16.2 \\
\hline 11 & Coyote Lake & 1979 & Strike slip & 5.7 & 9.6 & 37.085 & -121.505 & 10 & 3.1 & 33.8 \\
\hline 12 & Denali (Alaska) & 2002 & Strike slip & 7.9 & 4.9 & 63.538 & -147.444 & 24 & 2.7 & 275.9 \\
\hline 13 & Dinar (Turkey) & 1995 & Normal & 6.4 & 5.0 & 38.110 & 30.050 & 2 & 3.0 & 39.6 \\
\hline 14 & Düzce (Turkey) & 1999 & Strike slip & 7.2 & 10.0 & 40.740 & 31.210 & 23 & 0.2 & 188.7 \\
\hline 15 & Erzincan (Turkey) & 1992 & Strike slip & 6.9 & 9.0 & 39.720 & 39.630 & 2 & 5.0 & 65.0 \\
\hline 16 & Friuli (Italy) & 1976 & Reverse & 6.5 & 5.1 & 46.345 & 13.240 & 5 & 15.8 & 102.2 \\
\hline 17 & Gazli (Uzbekistan) & 1976 & Reverse & 6.8 & 10.0 & 40.381 & 63.472 & 1 & 5.0 & \\
\hline 18 & Racha (Georgia, USSR) & 1991 & Reverse & 6.2 & 9.0 & 42.461 & 44.009 & 8 & 37.0 & 155.0 \\
\hline 19 & Gulf of California & 2001 & Strike slip & 5.7 & 10.0 & 32.037 & -114.906 & 12 & 76.7 & 134.1 \\
\hline 20 & Hector Mine & 1999 & Strike slip & 7.1 & 5.0 & 34.574 & -116.291 & 213 & 10.7 & 259.3 \\
\hline 21 & Imperial Valley & 1979 & Strike slip & 6.5 & 10.0 & 32.644 & -115.309 & 33 & 0.1 & 50.1 \\
\hline 22 & Kocaeli (Turkey) & 1999 & Strike slip & 7.4 & 15.0 & 40.727 & 29.990 & 31 & 3.2 & 349.6 \\
\hline 23 & Landers & 1992 & Strike slip & 7.3 & 7.0 & 34.200 & -116.430 & 69 & 2.2 & 190.1 \\
\hline 24 & Lazio-Abruzzo (Italy) & 1984 & Normal & 5.8 & 14.0 & 41.710 & 13.902 & 5 & 18.9 & 51.3 \\
\hline 25 & Little Skull Mtn. (Nevada) & 1992 & Normal & 5.7 & 12.0 & 36.720 & -116.286 & 8 & 16.1 & 100.2 \\
\hline 26 & Livermore & 1980 & Strike slip & 5.8 & 12.0 & 37.855 & -121.816 & 7 & 16.7 & 56.1 \\
\hline 27 & Loma Prieta & 1989 & Reverse/strike slip & 6.9 & 17.5 & 37.041 & -121.883 & 82 & 3.9 & 117.1 \\
\hline 28 & Mammoth Lakes-02 & 1980 & Strike slip & 5.7 & 14.0 & 37.628 & -118.927 & 3 & 9.1 & 16.9 \\
\hline 29 & Mammoth Lakes-03 & 1980 & Strike slip & 5.9 & 16.0 & 37.561 & -118.831 & 4 & 5.9 & 11.5 \\
\hline 30 & Mammoth Lakes-04 & 1980 & Strike slip & 5.7 & 5.0 & 37.625 & -118.859 & 4 & 2.8 & 14.2 \\
\hline 31 & Mammoth Lakes-06 & 1980 & Strike slip & 5.9 & 14.0 & 37.506 & -118.856 & 5 & 12.0 & 46.5 \\
\hline 32 & Manjil (Iran) & 1990 & Strike slip & 7.4 & 19.0 & 36.810 & 49.353 & 7 & 12.6 & 174.6 \\
\hline 33 & Morgan Hill & 1984 & Strike slip & 6.2 & 8.5 & 37.306 & -121.695 & 28 & 0.5 & 70.9 \\
\hline 34 & Northridge & 1994 & Reverse & 6.7 & 17.5 & 34.206 & -118.554 & 174 & 4.0 & 78.1 \\
\hline 35 & North Palm Springs & 1986 & Strike slip/thrust & 6.1 & 11.0 & 34.000 & -116.612 & 32 & 8.6 & 268.0 \\
\hline 36 & Parkfield & 1966 & Strike slip & 6.2 & 10.0 & 35.955 & -120.498 & 6 & 6.3 & 63.3 \\
\hline 37 & Parkfield & 2004 & Strike slip & 6.0 & 8.8 & 35.819 & -120.364 & 94 & 0.3 & 169.6 \\
\hline 38 & San Fernando & 1971 & Reverse & 6.6 & 13.0 & 34.440 & -118.410 & 44 & 1.8 & 218.8 \\
\hline 39 & San Simeon & 2003 & Reverse & 6.5 & 7.1 & 35.702 & -121.108 & 138 & 12.4 & 317.8 \\
\hline 40 & Santa Barbara & 1978 & Thrust & 5.9 & 12.7 & 34.399 & -119.681 & 2 & 12.2 & 27.4 \\
\hline 41 & Sierra Madre & 1991 & Reverse & 5.6 & 12.0 & 34.259 & -118.001 & 9 & 10.4 & 48.2 \\
\hline 42 & Spitak (Armenia) & 1988 & Reverse & 6.8 & 5.0 & 40.987 & 44.185 & 1 & 25.0 & \\
\hline 43 & Superstition Hills-02 & 1987 & Strike slip & 6.5 & 9.0 & 33.022 & -115.831 & 11 & 1.0 & 27.0 \\
\hline 44 & Taiwan, Smart(5) & 1981 & Reverse & 5.9 & 11.1 & 24.429 & 121.896 & 7 & 28.7 & 32.0 \\
\hline 45 & Whittier Narrows & 1987 & Reverse & 6.0 & 14.6 & 34.049 & -118.081 & 116 & 14.5 & 103.9 \\
\hline 46 & Yountville & 2000 & Strike slip & 5.0 & 10.1 & 38.379 & -122.413 & 25 & 9.9 & 95.7 \\
\hline \multirow[t]{2}{*}{47} & Yucaipa & 2005 & Reverse & 4.9 & 11.6 & 34.058 & -117.011 & 388 & 2.6 & 160.1 \\
\hline & & & & & & & Total & 2,583 & & \\
\hline
\end{tabular}


mixed-effects residual analysis to demonstrate that our simpler functional form and limited number of estimation coefficients were sufficient enough to reach unbiased ground-motion estimates (Graizer and Kalkan, 2015).

In table 2, we summarize independent parameters of estimations for the three GMPEs. The distance metric for the GK15 and ASK14 GMPEs is the closest distance to the rupture plane, $R_{\text {rup }}$. The BSSA14 GMPE uses the closest distance to the horizontal projection of the rupture plane, $R_{\mathrm{JB}}$. ASK14 also uses $R_{\mathrm{JB}}$ for its hanging-wall function.

Each GMPE includes a SOF parameter according to its own faulting mechanism classification. The SOF parameter is dependent on earthquake magnitude for ASK14, whereas the SOF parameter of BSSA14 is magnitude independent. In the GK15 GMPE, the SOF parameter is adapted from Sadigh and others (1997) and is also magnitude independent. The ASK14 GMPE contains an explicit functional form for hanging-wall sites and a rupture depth term. The BSSA14 GMPE indirectly accounts for hanging-wall features through the use of $R_{\mathrm{JB}}$ without incorporating a rupture depth term, and locations over the fault plane have constant ground-motion values (Gregor and others, 2014). GK15 does not include a functional form for its hanging-wall effect.

All three GMPEs are defined for a range of $V_{\mathrm{S} 30}$ values (see table 2). In ASK14, numerical simulations of nonlinear site amplification factors by Kamai and others (2014) were used to constrain the site response. In BSSA14, a semiempirical nonlinear site response model by Seyhan and Stewart (2014) was used; this model is based on empirical data and simulations of Kamai and others (2014). For a reference site condition, the nonlinear site amplification factor is a function of PGA for BSSA14 and of SA for ASK14. The GK15 GMPE contains a linear site amplification feature based on the more limited $V_{\mathrm{S} 30}$ range. In addition to

Table 2. Summary of databases, intensity measures, and applicability ranges of independent predictors for three ground-motion prediction equations.

[Ground-motion prediction equations are GK15, Graizer and Kalkan (2015, 2016); ASK14, Abrahamson and others (2014); BSSA14, Boore and others (2014). PGA, peak ground acceleration; PGV, peak ground velocity; SA; spectral acceleration; s, seconds; SS, strike slip; REV, reverse; NM, normal; U, unspecified; $\mathrm{km}$, kilometers; $V_{\mathrm{S} 30}$, shear-wave velocity in upper 30 meters of geologic profile; $\mathrm{m} / \mathrm{s}$, meters per second; km/s, kilometers per second]

\begin{tabular}{|c|c|c|c|}
\hline Item & GK15 & ASK14 & BSSA14 \\
\hline Database & Expanded NGA-West1 & NGA-West2 & NGA-West2 \\
\hline Number of events (for PGA) & 47 & 326 & 404 \\
\hline Number of recordings (for PGA) & 2,583 & 15,750 & 18,436 \\
\hline Intensity measures & PGA, SA & PGA, PGV, SA & PGA, PGV, SA \\
\hline Period range (s) & $0.01-5$ & $0.01-10$ & $0.01-10$ \\
\hline Period definition (number of periods) & Continuous & Discrete (21) & Discrete (42) \\
\hline Number of estimation coefficients & 31 & 1,008 & 2,889 \\
\hline Number of independent predictors & 7 & 7 & 6 \\
\hline Class 2 event flag & Unused & Included & Unused \\
\hline \multirow[t]{2}{*}{ Magnitude (style of faulting) } & 5.0-8.0 (SS, REV) & $3.0-8.5$ (all) & 3.0-8.5 (SS, REV) \\
\hline & $7.0-8.0(\mathrm{NM})$ & & $3.3-7.0(\mathrm{NM})$ \\
\hline Style of faulting & SS, REV, NM & SS, REV, NM & SS, REV, NM, U \\
\hline Dip & Unused & Used & Unused \\
\hline Down-dip rupture width & Unused & Used & Unused \\
\hline Closest distance to rupture plane $(\mathrm{km})$ & $0-250$ & $0-300$ & Unused \\
\hline Joyner-Boore distance (km) & Unused & Unused & $0-400$ \\
\hline $\begin{array}{l}\text { Horizontal distance to top edge of rupture plane measured } \\
\text { perpendicular to strike }\end{array}$ & Unused & Used & Unused \\
\hline $\begin{array}{l}\text { Horizontal distance to top edge of rupture plane measured } \\
\text { parallel to strike }\end{array}$ & Unused & Used & Unused \\
\hline $\mathrm{V}_{\mathrm{S} 30}(\mathrm{~m} / \mathrm{s})$ & $200-1,300$ & $180-1,500$ & $150-1,500$ \\
\hline Depth to $1.0 \mathrm{~km} / \mathrm{s}$ isosurface & Unused & Used & Used \\
\hline Depth to $1.5 \mathrm{~km} / \mathrm{s}$ isosurface & Used & Unused & Unused \\
\hline Depth to basin & Used & Used & Used \\
\hline Nonlinear site effects & Unused & Used & Used \\
\hline Quality factor & Used & Unused & Unused \\
\hline Hanging wall & Unused & Used & Indirectly used \\
\hline Regional adjustment & Used & Used & Used \\
\hline Standard deviation (total, intra, inter) & Used & Used & Used \\
\hline
\end{tabular}


the $V_{\mathrm{S} 30}$ parameter, ASK14 and BSSA14 also incorporate a parameter that is dependent on the depth to the $1.0 \mathrm{~km} / \mathrm{s}$ shear-wave isosurface $\left(Z_{1.0}\right)$ and GK15 uses the depth to the $1.5 \mathrm{~km} / \mathrm{s}$ shear-wave isosurface $\left(Z_{1.5}\right)$. These extra parameters are to capture the difference in site amplification from deep sedimentary basins. Furthermore, ASK14 uses the depth to the top of rupture $\left(Z_{\mathrm{TOR}}\right)$, whereas GK15 and BSSA14 found a depth parameter to be insignificant for ground-motion prediction with their mathematical forms.

The NGA-West2 project (Bozorgnia and others, 2014) and recent earthquake data (for example, Baltay and Boatwright, 2015) signify regionalization when accounting for differences in far-source distance attenuation of ground motions and site response. Hence, ASK14 and BSSA14 have developed regional adjustments for either site response and (or) the long-distance anelastic attenuation between various geographic regions. BSSA14 incorporated only the regional attenuation adjustment feature. GK15 uses $Q_{0}$ - determined using $L g$ or coda wavesas an independent predictor that can be changed to suit the region of interest.

\section{Stage 1: Comparisons of Median Predictions}

In the following sections, we compared the distance-scaling features, magnitude-scaling features, SOF effects, site effects, response spectra (shape and amplitude), and standard deviations of ASK14, BSSA14, and GK15.

\section{Distance-Scaling Features}

Figures $1 A$ and $2 A$ show a comparison of the distancescaling features of the median estimates of PGA and SA at 0.2, 1.0 , and 3.0 seconds (s) for horizontal ground motions predicted by the three GMPEs for vertically dipping strike-slip earthquake scenarios with $M 5,6,7$, and 8 as a function of $R_{\text {rup }}$ for ASK14 and GK15 and as a function of $R_{\mathrm{JB}}$ for BSSA14. Note that $R_{\text {rup }}$ and $R_{\mathrm{JB}}$ are the same for vertical strike-slip events with the depth to top of the rupture equal to zero (for brevity, we did not include a comparison for dip-slip faults). The results are for National Earthquake Hazards Reduction Program (NEHRP) classes $\mathrm{B}$ and $\mathrm{C}$ reference site conditions $\left(V_{\mathrm{S} 30}=760\right.$ meters per second $[\mathrm{m} / \mathrm{s}]$, in other words, engineering rock). These scenarios were chosen because the magnitude range, strike-slip faulting mechanism, and $\mathrm{B} / \mathrm{C}$ reference site conditions are the most common for hazard computations in California (Petersen and others, 2014). For this comparison, ASK14 is evaluated for default values of $Z_{1.0}(0.0481 \mathrm{~km})$ and $Z_{\text {TOR }}(6 \mathrm{~km}$ for $M 5$, $3 \mathrm{~km}$ for $M 6,1 \mathrm{~km}$ for $M 7$, and $0 \mathrm{~km}$ for $M 8$ ) and BSSA 14 is evaluated for a default value of $\delta_{\mathrm{z} 1}(0)$; these values were adapted from Gregor and others (2014). The region parameter is set to 1 for ASK14 and 0 for BSSA14 considering California. The GK15 GMPE is evaluated for a regional $Q_{0}$ of 150 , which is an average for California (Singh and Herrmann, 1983; Mitchell and Hwang, 1987; Erickson and others, 2004).

Figures $1 A$ and $2 A$ also illustrate short-distance saturation as a function of magnitude for the three GMPEs. For PGA and SA at $0.2 \mathrm{~s}$, GK15 produces similar or slightly lower median results compared to ASK14 and BSSA14 at close distances (0-2 km). The GK15 GMPE produces higher median predictions because of oversaturation of attenuation (bump) between 2 and $15 \mathrm{~km}$. The bump phenomenon (also called oversaturation of attenuation) was recently demonstrated through modeling geometric spreading and relative amplitudes of ground motions in eastern North America. The bump was attributed to radiation pattern effects combined with wave propagation through a one-dimensional layered earth model (Chapman and Godbee, 2012; Baumann and Dalguer, 2014). In the case of earthquakes, this bump can be the result of one or many factors, including the aforementioned radiation pattern, directivity and nonlinear behavior of soil near a fault source (for example, low-velocity faultzone-guided waves [Li and Vidale, 1996]), and by measuring distance as that closest to the rupture plane and not from the seismogenic (most energetic) part of the fault rupture.

To quantify the differences for a range of magnitudes and distances, figure $1 B$ presents the ratio between median predictions of GK15 and those of ASK14. The upper and lower bounds of the shaded areas indicate a factor of 2 difference. The median predictions of GK15 are generally similar to those of ASK14 within a factor of 1.5 for PGA and SA at $0.2 \mathrm{~s}$ within about $30 \mathrm{~km}$ for $M 5$ events, about $45 \mathrm{~km}$ for $M 6$ events, and about $150 \mathrm{~km}$ for $M 7$ and $M 8$ events. For these intensity measures, the difference becomes more than 2 only for $M 5$ events beyond $50 \mathrm{~km}$ and $M 6$ events beyond about $90 \mathrm{~km}$. At $150 \mathrm{~km}$, the difference in PGA is less than 2.5 for $M 6$ events and 4 for $M 5$ events. For SA at $0.2 \mathrm{~s}$, the difference at $150 \mathrm{~km}$ is 3 for $M 6$ events and more than 4 for $M 5$ events. For SA at 1.0 and $3.0 \mathrm{~s}$, the difference between the GK15 median predictions and those of ASK14 are, in general, within a factor of 2.5 except for $M 5$ events beyond about 40 $\mathrm{km}$ for SA at $1.0 \mathrm{~s}$ and beyond about $75 \mathrm{~km}$ for SA at $3.0 \mathrm{~s}$. At $150 \mathrm{~km}$, the largest difference for $M 5$ events becomes 3.7 for SA at $1.0 \mathrm{~s}$ and 2.7 for $\mathrm{SA}$ at $3.0 \mathrm{~s}$.

Figure $2 B$ shows the ratios between the GK15 and BSSA14 median predictions. For PGA and SA at $0.2 \mathrm{~s}$, the difference is within a factor of 1.5 for $M 6,7$, and 8 events within $150 \mathrm{~km}$. For SA at 1.0 and $3.0 \mathrm{~s}$, this difference is within a factor of 2. The main difference between the GK15 and BSSA14 predictions is for $M 5$ events for SA at 1.0 and $3.0 \mathrm{~s}$, which is within a factor of 3.5.

\section{Magnitude-Scaling Features}

The effect of magnitude scaling for vertical strike-slip earthquakes at distances of 10,30 , and $150 \mathrm{~km}$ is shown in figure 4 for $V_{\mathrm{S} 30}=760 \mathrm{~m} / \mathrm{s}$ for median predictions of PGA and SA at $0.2,1.0$, and $3.0 \mathrm{~s}$ by the three GMPEs. ASK14 and BSSA14 were evaluated for default values, as described previously. The magnitude range is from 5 to 8 . Note that the 

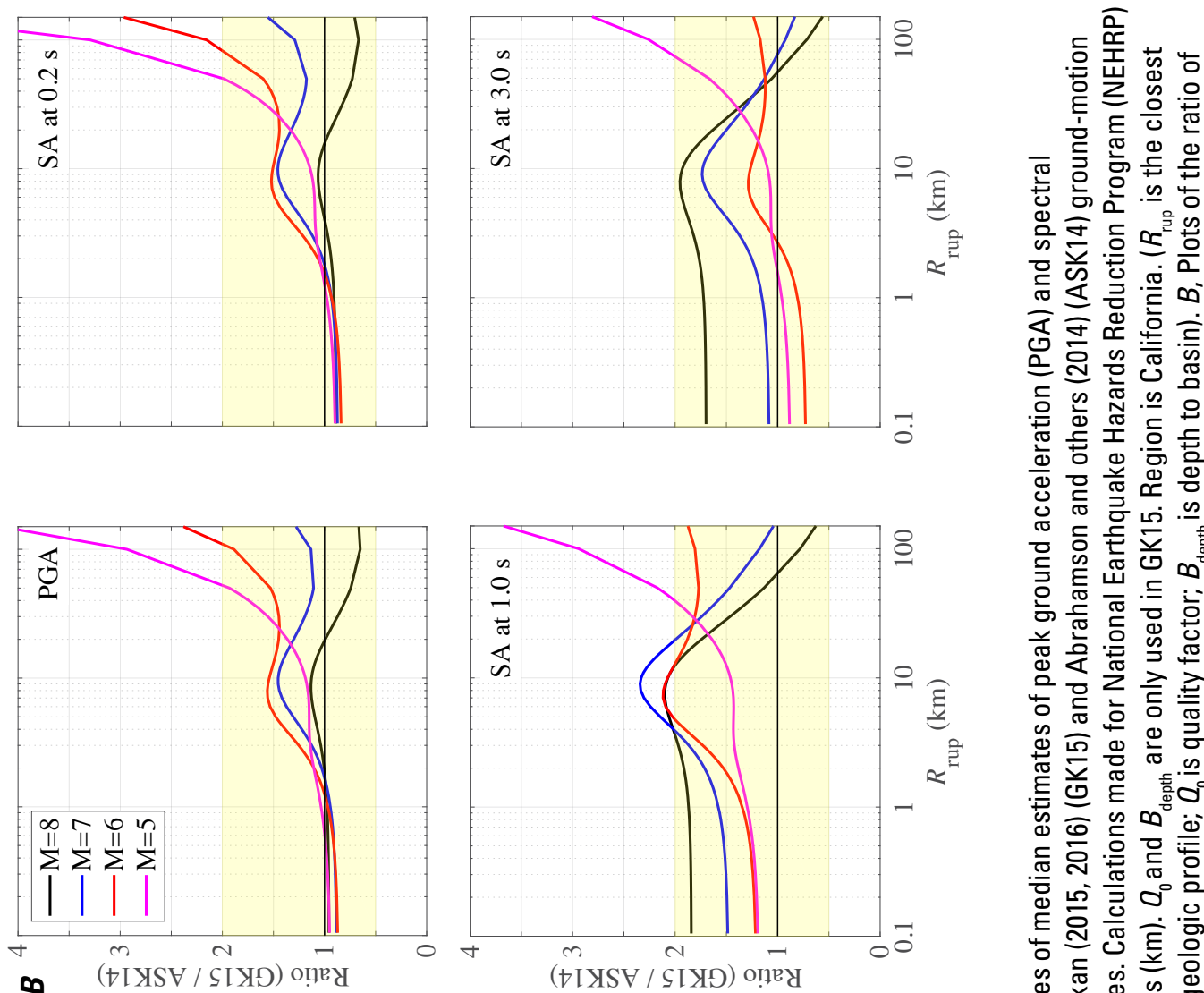

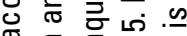

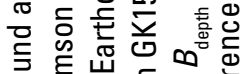

임 元

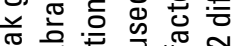

造茫艺艺

论 등 흥

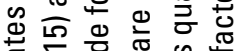

䒕 立 苋

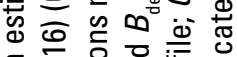

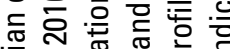

훙

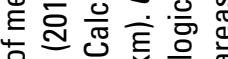

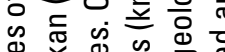

凹 ฐ

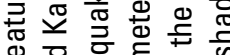

世 든 든 는

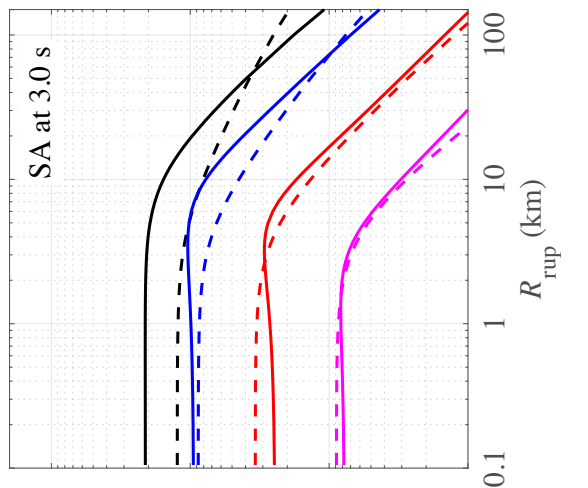

음 ฮ

范 $\frac{N}{\pi} \|$

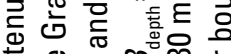

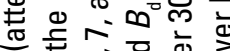

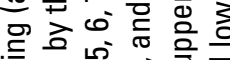

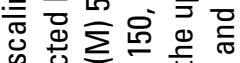

d่

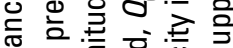

홓ㄷㅎㅇ응

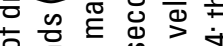

○

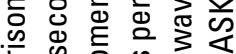

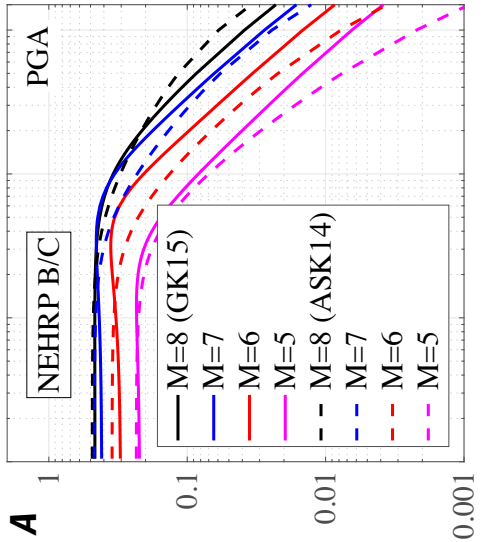

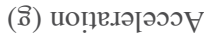

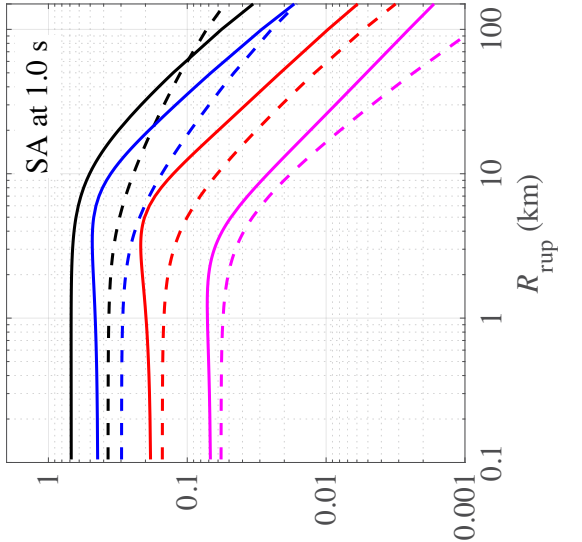

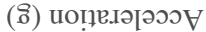

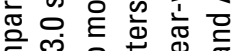

등 을 을 든

ర

ठठ

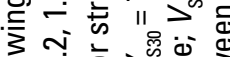

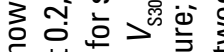

क 木

흐은 흔 곤

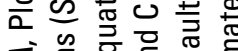

ব

- 产

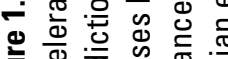

可式 

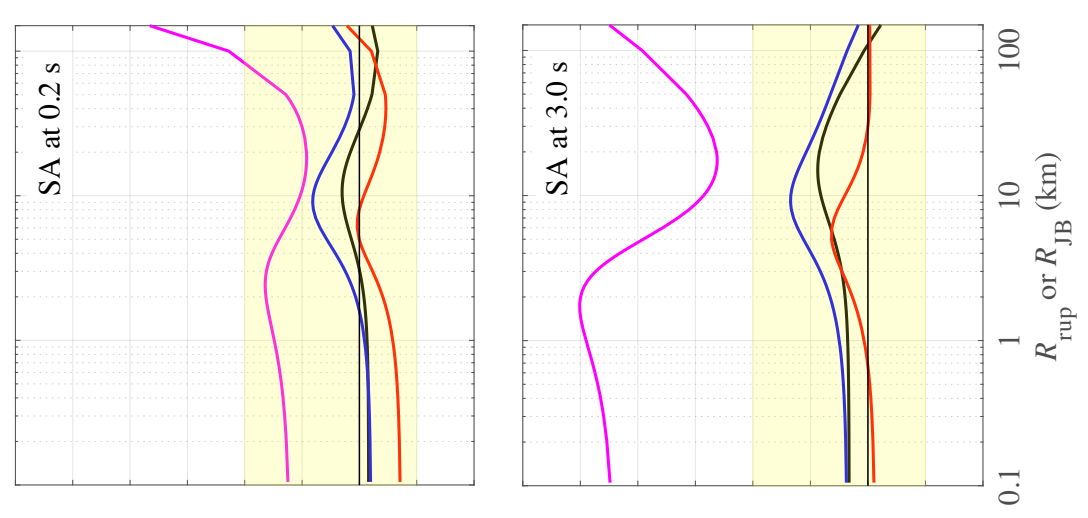

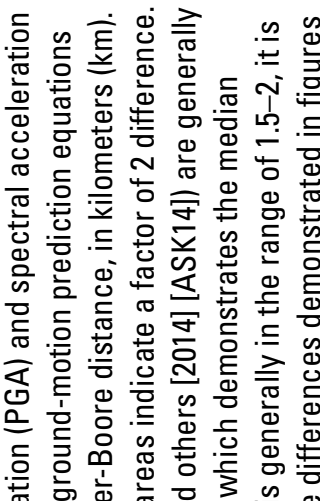

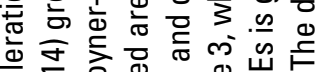
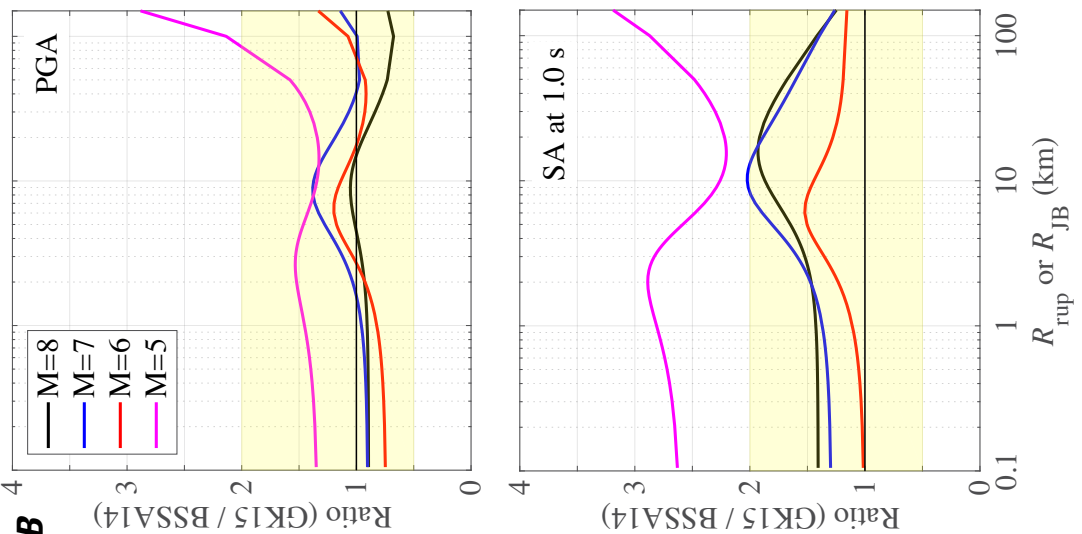

过立市站

ठ্ঠ

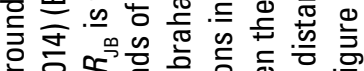

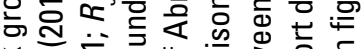

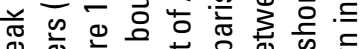

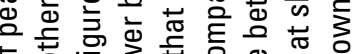

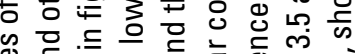

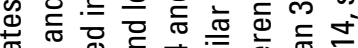

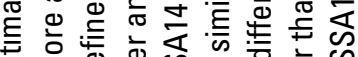
ळ 웡 ळ

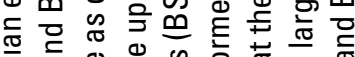

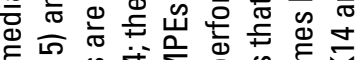

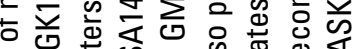
क 屯 ఏ
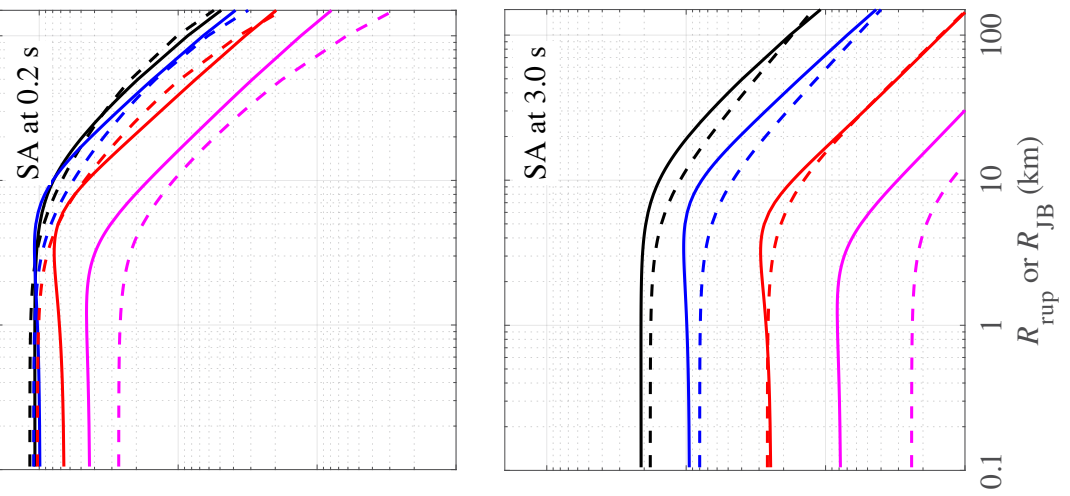

吾

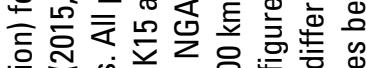

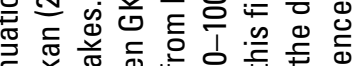

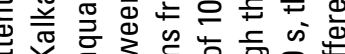

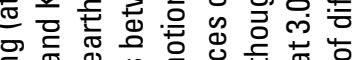

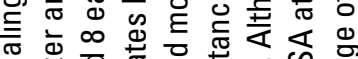

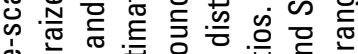

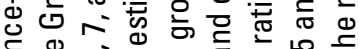

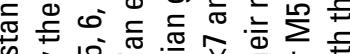

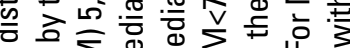
प

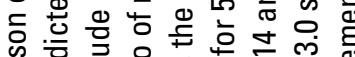

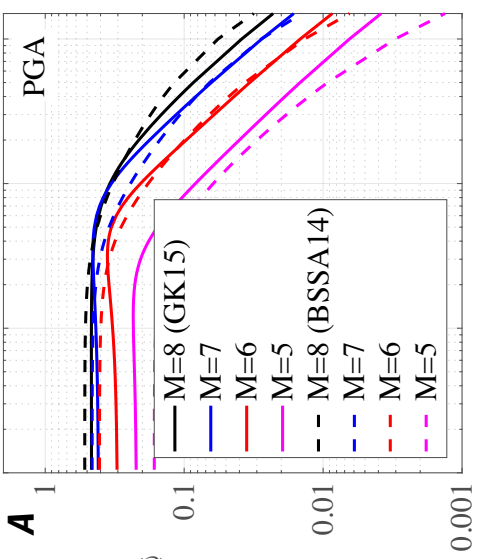

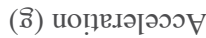

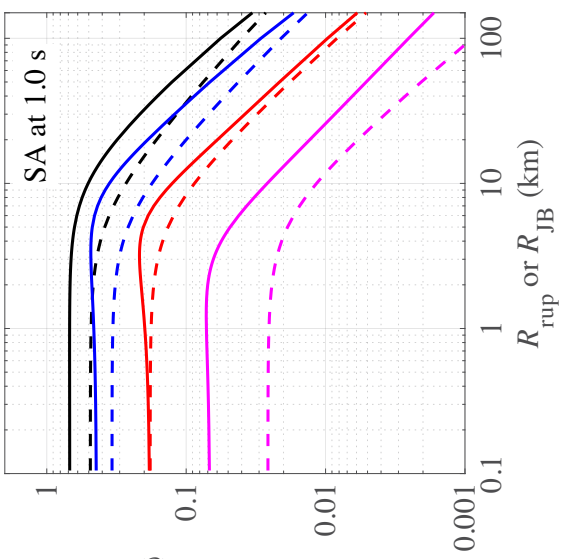

(ฮ) นоце.әวәวю
象 d

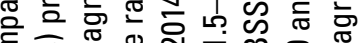
ธิ

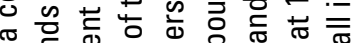

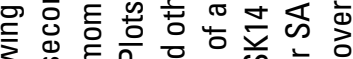

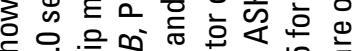
क位

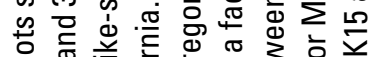

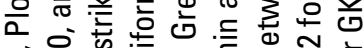
ব은

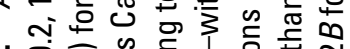

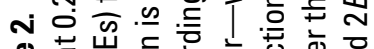

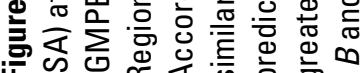



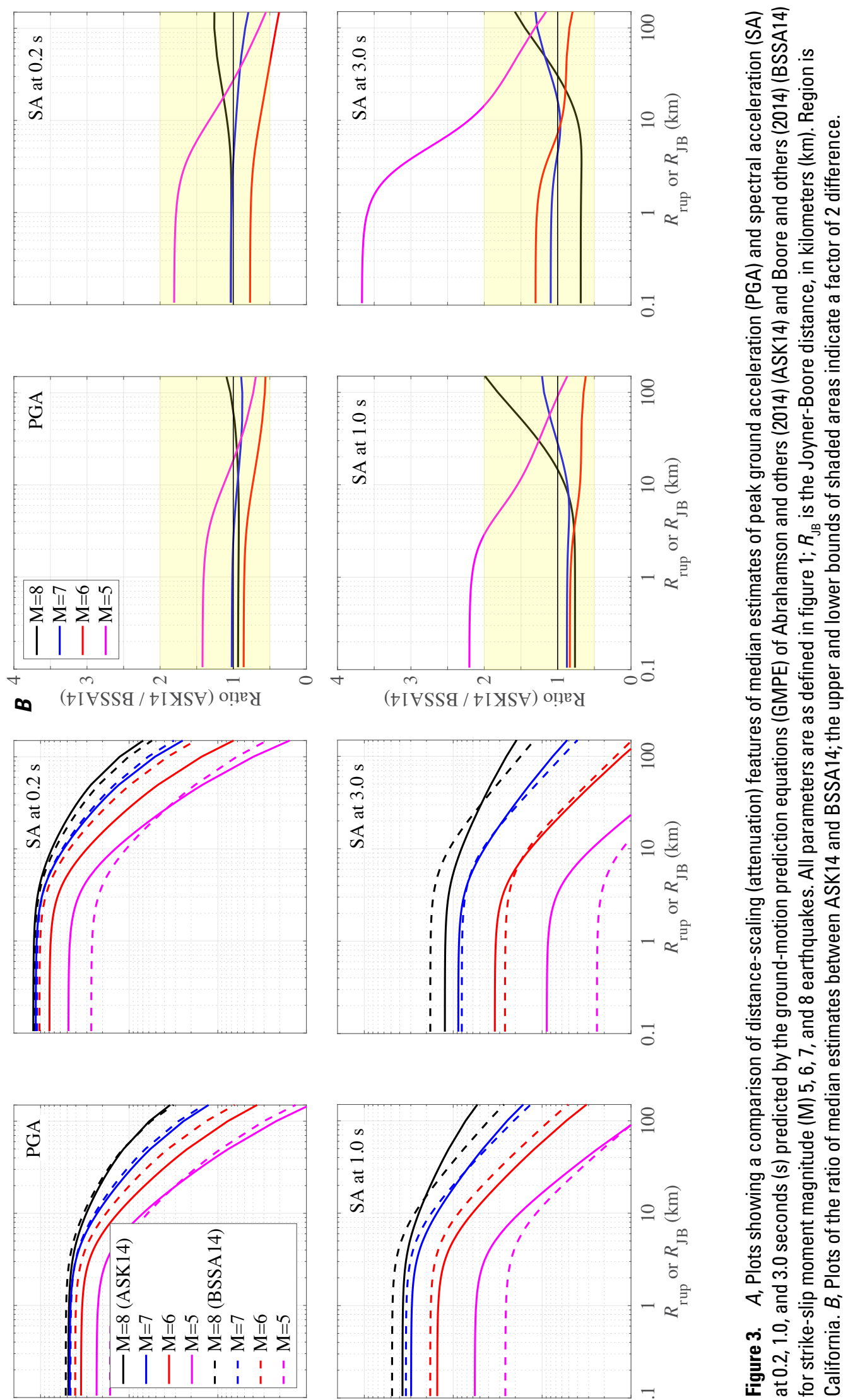

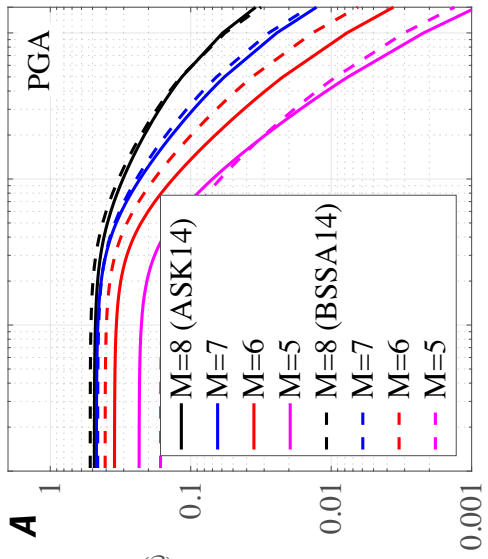

(ฮ) นоฺฺฺ.วววว

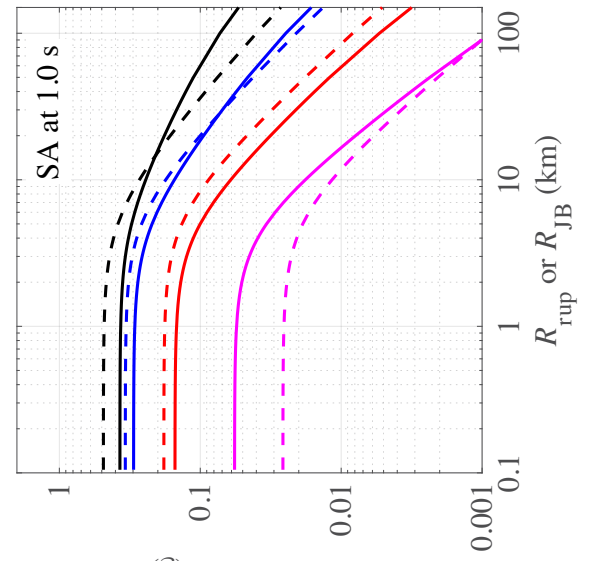

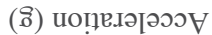



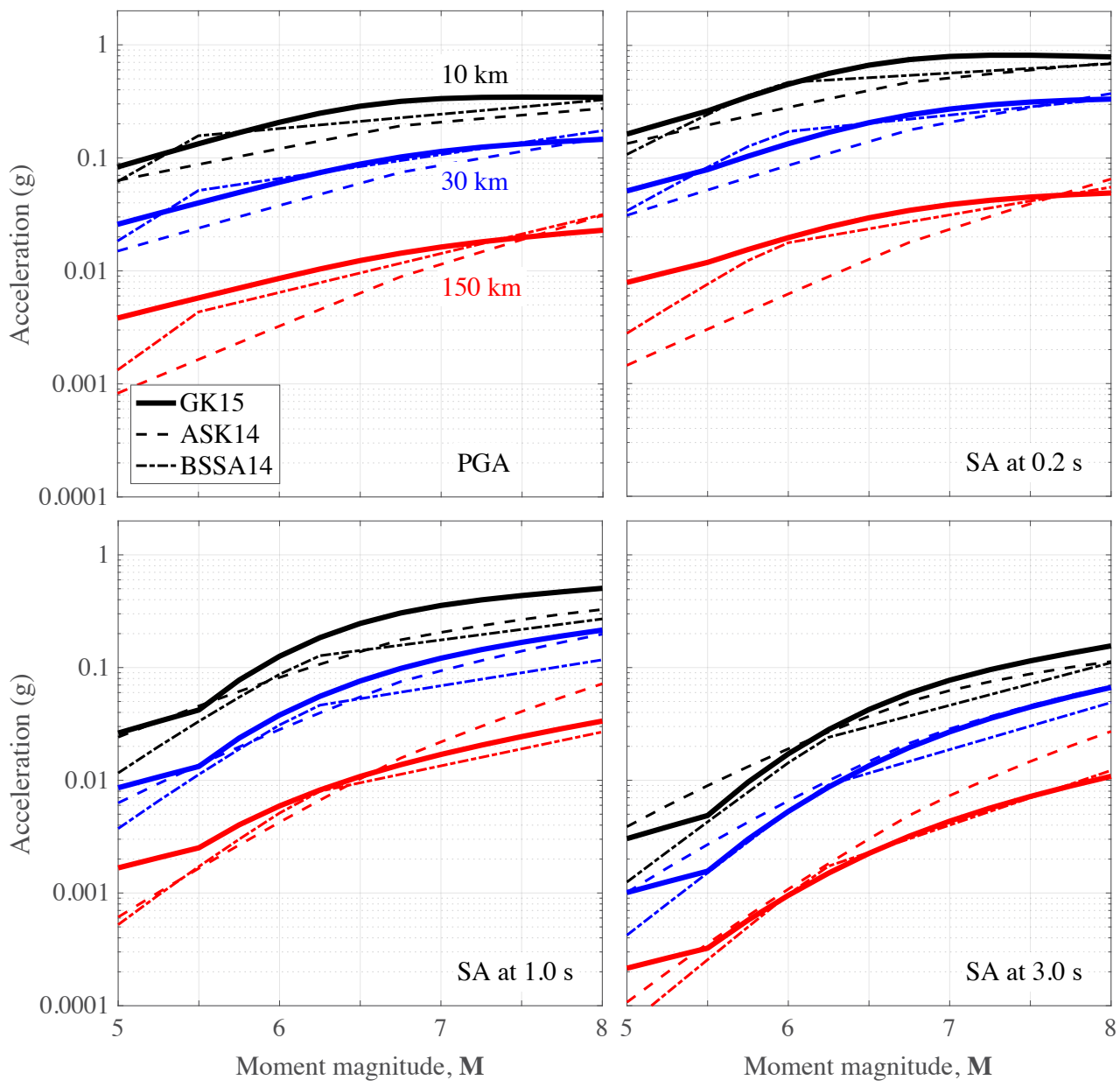

Figure 4. Plots showing a comparison of magnitude (M) scaling features of median estimates of peak ground acceleration (PGA) and spectral acceleration $(S A)$ at $0.2,1.0$, and 3.0 seconds (s) by the groundmotion prediction equations of Graizer and Kalkan $(2015,2016)$ (GK15), Abrahamson and others (2014) (ASK14), and Boore and others (2014) (BSSA14) for 10, 30, and 150 kilometers $(\mathrm{km})$. Region is California. All parameters are as defined in figure 1. break in the magnitude scaling of GK15 at M5.5 is driven by the spectral shape of records used to constrain the magnitudescaling function. The weak scaling of the short-period motion at short distances reflects the saturation with magnitude, which is common to all three GMPEs. The magnitude-scaling features of these GMPEs show similarities and differences depending on the intensity measure and magnitude level. For instance, the median ground motions are within a factor of 2 for short periods (PGA and SA at $0.2 \mathrm{~s}$ ) for M6 events and larger. At long periods, the range increases to a factor of 3 at M6 events and larger.

The differences between model predictions are greater for $M 5$ events, especially at $150 \mathrm{~km}$ distance. We attribute these dissimilarities to regional variations and data used in constraining the GMPEs. In the case of GK15, 97.9 percent of small-magnitude $(4.9 \leq M<6)$ earthquake data were from California (table 1) and the remaining 3.1 percent were from Nevada, Italy, and Taiwan. In contrast, the ASK14 and BSSA14 GMPEs used small-magnitude event data from other regions in larger percentages. Recent studies have shown that small- to moderate-magnitude events have different attenuation trends compared with moderate- to large-magnitude events (Chiou and others, 2010; Atkinson and Morrison, 2009) and the regional variation is even more significant for smaller magnitude events (Zafarani and Farhadi, 2017).

\section{Site Effects}

All three GMPEs use $V_{\mathrm{S} 30}$ for modeling site response scaling. A comparison of median spectrum as a function of $V_{\text {S30 }}$ values is shown in figure 5 for a $M 7$ vertical strike-slip earthquake at the closest distances to the rupture plane of 10 and $50 \mathrm{~km}$. For ASK14, $Z_{\mathrm{TOR}}$ is $1 \mathrm{~km}$ and for other parameters, including $Z_{1.0}$ and $Z_{2.5}$, the default values of ASK14 and BSSA14 are used. The GK15 GMPE is limited to $V_{\mathrm{S} 30} \geq 200 \mathrm{~m} / \mathrm{s}$ and does not contain a nonlinear site amplification term because of the large variability in nonlinear site-correction models.

For higher $V_{\mathrm{S} 30}$ values, ASK14 and BSSA14 saturate by predicting constant ground-motion values. For shorter distances $(<10 \mathrm{~km})$, the nonlinear effects are apparent by the observed curvature in the amplification functions for ASK14 and BSSA14, especially for PGA and SA at 0.2 s. Overall, the site amplification results are alike among the three GMPEs; the largest difference is 35 percent between GK15 and the other two GMPEs at $200 \mathrm{~m} / \mathrm{s}$ for SA at $0.2 \mathrm{~s}$. 
Figure 5. Plots showing a comparison of $V_{\mathrm{S} 30}$-scaling features of the median estimates of peak ground acceleration (PGA) and spectral acceleration (SA) at $0.2,1.0$, and 3.0 seconds (s) by the ground-motion prediction equations of Graizer and Kalkan $(2015,2016)$ (GK15), Abrahamson and others (2014) (ASK14), and Boore and others (2014) (BSSA14) for a magnitude 7 strike-slip earthquake at 10 and 50 kilometers $(\mathrm{km}) . V_{\mathrm{s} 30}$ is in units of meters per second $(\mathrm{m} / \mathrm{s})$. Region is California. All parameters are as defined figure 1.
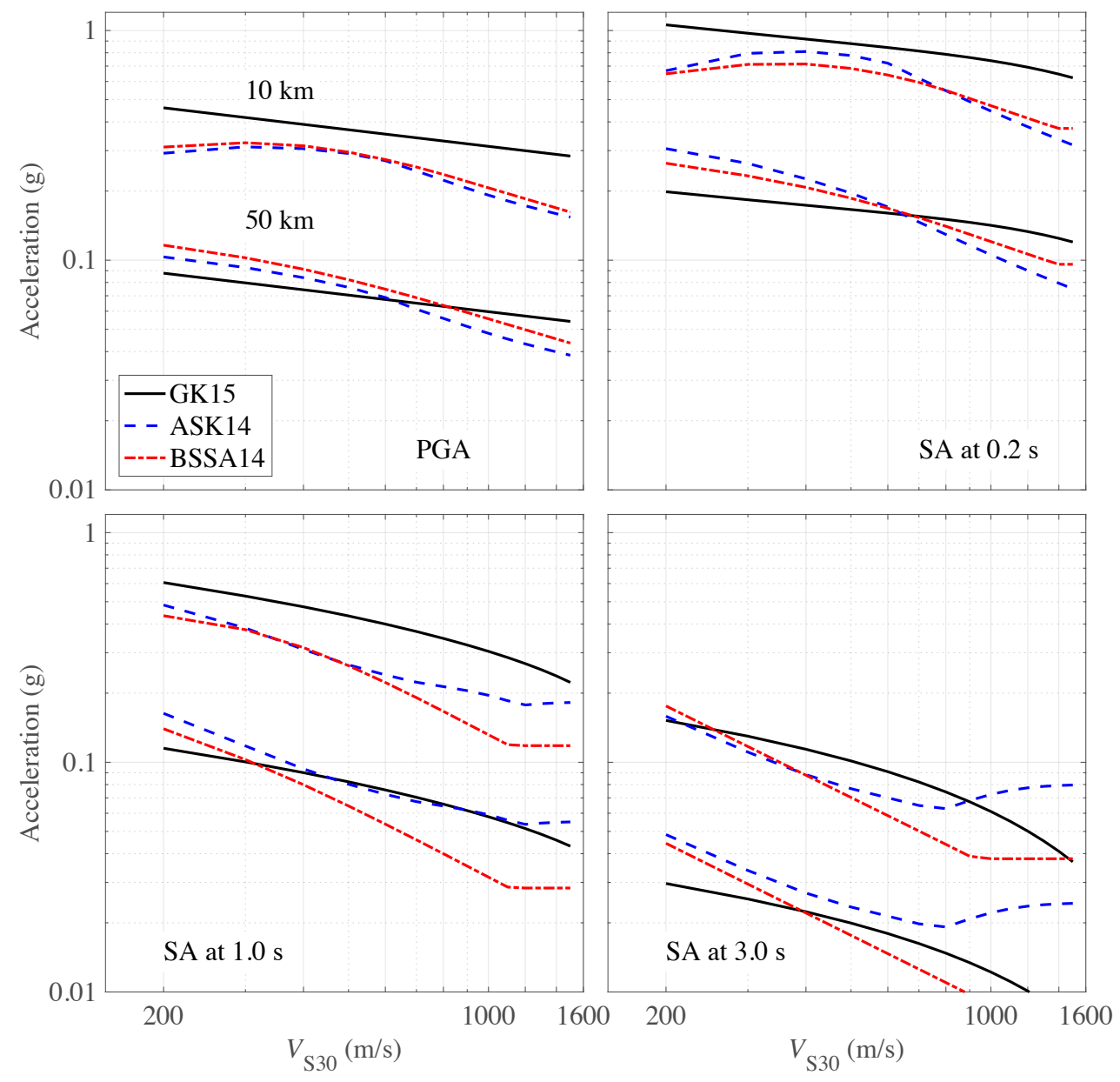

\section{Style-of-Faulting Effects}

Figure 6 compares SOF ratios between reverse and strike-slip events and between normal and strike-slip events for the period range of 0.01 to $5 \mathrm{~s}$ at $30 \mathrm{~km}$. These ratios are computed for a $M 7$ event. In GK15, the SOF factor is period and magnitude independent. In ASK14, a magnitude-dependent but period-independent SOF factor was used for reverse and normal earthquakes only. In BSSA14, a magnitude-dependent SOF factor, which is a function of the period-dependent "hinge magnitude," was used for unspecified, strike-slip, reverse, and normal faults. GK15 predicts larger reverse/strike-slip ratios than either ASK14 or BSSA14. For reverse/strike-slip ratios, the difference between ASK14 and BSSA14 are less than 10 percent, except at long periods. For normal/strike-slip ratios, the difference between ASK14 and BSSA14 are larger for short periods and smaller at long periods. These comparisons suggest that there is a noteworthy variation.

\section{Response Spectra}

A comparison between the linear site-effect scaling features of the GK15 GMPE and the ASK14 and BSSA14 GMPEs is shown in figure 7 for a $M 7$ strike-slip event at a distance of $30 \mathrm{~km}$ for a range of $V_{\mathrm{S} 30}$ values representing NEHRP soil classifications $\mathrm{B}\left(V_{\mathrm{S} 30}=750\right.$ to $\left.1,200 \mathrm{~m} / \mathrm{s}\right), \mathrm{C}\left(V_{\mathrm{S} 30}=450\right.$ to $\left.750 \mathrm{~m} / \mathrm{s}\right)$, and D $\left(V_{\mathrm{S} 30}=250\right.$ to $\left.450 \mathrm{~m} / \mathrm{s}\right)$. The independent estimation parameters used in figure 1 were repeated.

The spectral shapes from the three GMPEs are similar between 0.01 and $3.0 \mathrm{~s}$. The GK15 GMPE shows faster decay at long periods ( 3.0 to $5.0 \mathrm{~s}$ ), as controlled by the decay term in the spectral shape prediction model, which is a function of basin depth. As compared to the ASK14 and BSSA14 GMPEs, variations in site effects owing to different site classes are less pronounced in the GK15 GMPE, but the overall spectral shapes are analogous.

The median response spectra predicted by GK 15 for $M 6$, 7 , and 8 earthquakes at 1 and $30 \mathrm{~km}$ from a vertically dipping strike-slip fault with $V_{\mathrm{S} 30}=760$ and $270 \mathrm{~m} / \mathrm{s}$ are compared with those predicted by ASK 14 and BSSA14 in figures 8 and 9 , respectively. Again, the default parameters shown in figure 1 were repeated. There is resemblance (within a factor of 1.5) among the three models for the $M 6-8$ cases. The difference between GK15 and ASK14 increases to a factor of 2 for the $M 8$ case, especially at $1.0 \mathrm{~s}$ for $V_{\mathrm{S} 30}=760 \mathrm{~m} / \mathrm{s}$; this difference is much less for $V_{\mathrm{S} 30}=270 \mathrm{~m} / \mathrm{s}$. The largest relative change in the response spectra between GK15 and BSSA14 is for long 

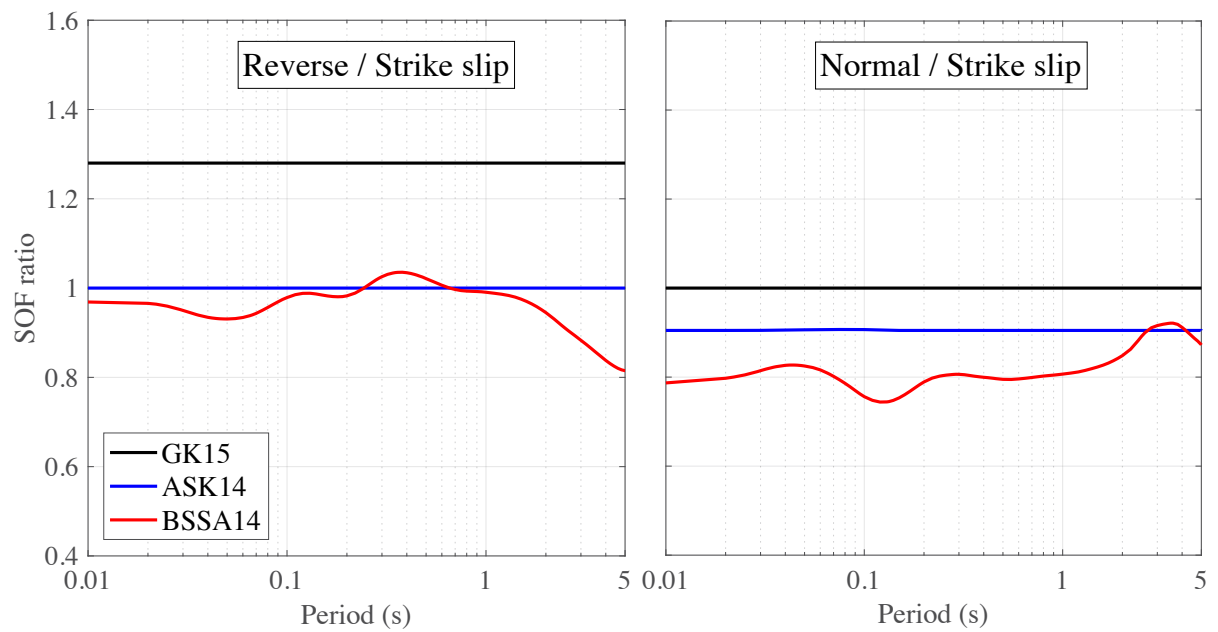

Figure 6. Plots showing a comparison of style-of-faulting (SOF) ratios versus period (in seconds [s]) between reverse and strike-slip events and between normal and strikeslip events at 30 kilometers $(\mathrm{km})$ among the Graizer and Kalkan $(2015,2016)$ (GK15), Abrahamson and others (2014) (ASK14), and Boore and others (2014) (BSSA14) groundmotion prediction equations.

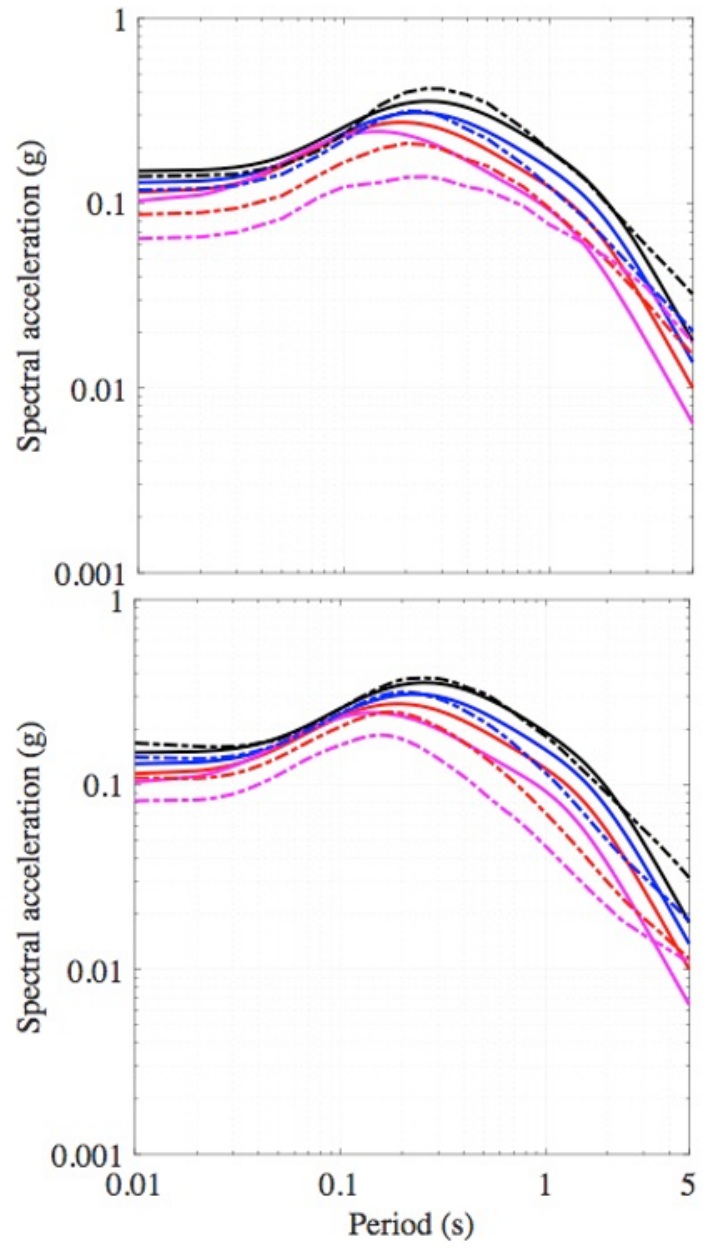

GK15

$-V_{\mathrm{S} 30}=250 \mathrm{~m} / \mathrm{s}$

$-V_{\mathrm{S} 30}=450 \mathrm{~m} / \mathrm{s}$

$-V_{\mathrm{S} 30}=750 \mathrm{~m} / \mathrm{s}$

$-V_{\mathrm{S} 30}=1,200 \mathrm{~m} / \mathrm{s}$

ASK14

-. $V_{\mathrm{S} 30}=250 \mathrm{~m} / \mathrm{s}$

.-. $V_{\mathrm{S} 30}=450 \mathrm{~m} / \mathrm{s}$

-.. $V_{\mathrm{S} 30}=750 \mathrm{~m} / \mathrm{s}$

-.. $V_{\mathrm{S} 30}=1,200 \mathrm{~m} / \mathrm{s}$

GK15

$-V_{\mathrm{S} 30}=250 \mathrm{~m} / \mathrm{s}$

$-V_{\mathrm{S} 30}=450 \mathrm{~m} / \mathrm{s}$

$-V_{\mathrm{S} 30}=750 \mathrm{~m} / \mathrm{s}$

$-V_{\mathrm{S} 30}=1,200 \mathrm{~m} / \mathrm{s}$

BSSA14

. -. $V_{\mathrm{S} 30}=250 \mathrm{~m} / \mathrm{s}$

.-. $V_{\mathrm{S} 30}=450 \mathrm{~m} / \mathrm{s}$

-.. $V_{\mathrm{S} 30}=750 \mathrm{~m} / \mathrm{s}$

.-. $V_{\mathrm{S} 30}=1,200 \mathrm{~m} / \mathrm{s}$
Figure 7. Plots showing a comparison of $V_{\mathrm{S30}}$-scaling features of the median estimates of response-spectral shapes and amplitudes versus period (in seconds [s]) among the Graizer and Kalkan (2015, 2016) (GK15), Abrahamson and others (2014) (ASK14), and Boore and others (2014) (BSSA14) ground-motion prediction equations for a strike-slip magnitude 7 earthquake at 30 kilometers $(\mathrm{km}) . V_{\mathrm{S} 30}$ is in units of meters per second $(\mathrm{m} / \mathrm{s})$. All parameters are as defined in figure 1. 
Figure 8. Plots showing a comparison of the median estimates of response-spectral shapes and amplitudes versus period (in seconds [s]) between the Graizer and Kalkan $(2015,2016)$ (GK15) and Abrahamson and others (2014) (ASK14) ground-motion prediction equations for strike-slip magnitudes 6,7 , and 8 earthquakes at a rupture distance $\left(R_{\text {rup }}\right)$ of 1 and 30 kilometers $(\mathrm{km})$. Comparisons are shown for $V_{\mathrm{s} 30}$ equal to 270 and 760 meters per second $(\mathrm{m} / \mathrm{s})$. All parameters are as defined figure 1.
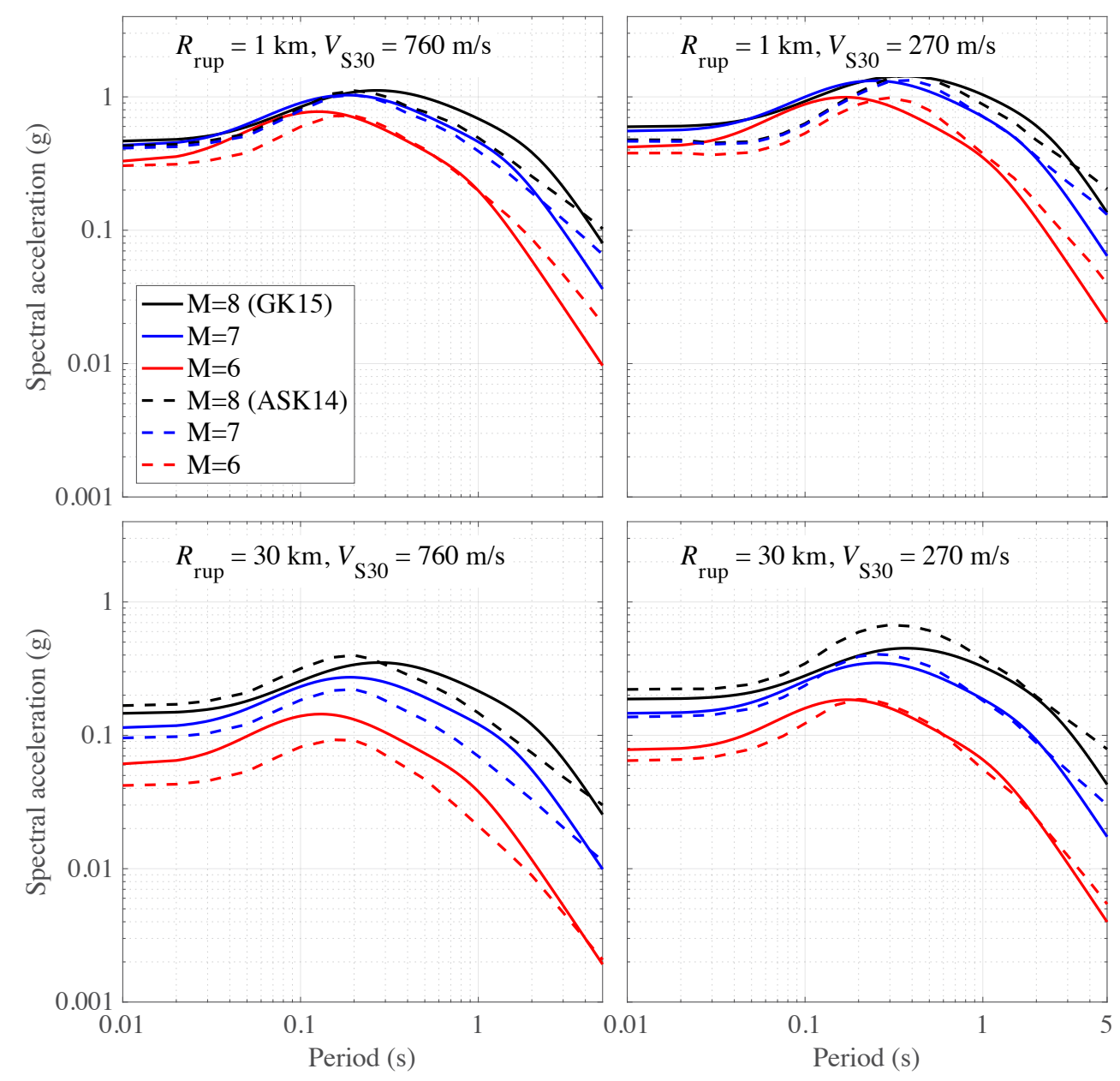

periods. For intermediate and short periods, the range in GK15 predictions is similar to BSSA14. For the $M 6$ case, the response spectra predictions are generally similar between the GK15 and BSSA14 GMPEs, except for $V_{\mathrm{s} 30}=270 \mathrm{~m} / \mathrm{s}$ at $30 \mathrm{~km}$, where the differences are noticeable for a wide range of periods.

\section{Standard Deviations}

Figure 10 compares the period dependence of the standard deviations among GK15, ASK14, and BSSA14 for a M5 vertical strike-slip event at $30 \mathrm{~km}$ and $V_{\mathrm{S} 30}=760 \mathrm{~m} / \mathrm{s}$. All standard deviations $(\sigma)$ are in natural logarithmic units. Only the standard deviations of ASK14 are magnitude dependent. GK15 standard deviations are generally lower than the other two GMPEs between 0.01 and $0.7 \mathrm{~s}$. At $1.0 \mathrm{~s}, \sigma$ is similar between the three GMPEs. For longer spectral periods ( $>1.0 \mathrm{~s}$ ), GK15 has larger $\sigma$ than the other two GMPEs. Differences are greater for intra-event standard deviations $(\phi)$ than inter-event standard deviations $(\tau)$. Large $\phi$ values for ASK14 and BSSA14 suggest potential supplementary variability in PGA and SA owing to the additional events included in the NGA-West2 database. The ASK14 GMPE shows generally flat $\tau$ trends with period, whereas the trends of $\tau$ for GK15 and BSSA14 are similar and fluctuate with period. The GK15 GMPE has lower values of $\phi$ than the other GMPEs at periods less than $0.7 \mathrm{~s}$ with the overall impact on $\sigma$ at the lowest values of $\sigma$.

\section{Stage 2: Comparisons with Earthquake Data}

In figures 11-13, SA predictions between 0.01 and $5 \mathrm{~s}$ from the three GMPEs are compared with the response spectra for near-field ( 0 to $20 \mathrm{~km})$ and intermediate-field (50 to $70 \mathrm{~km}$ ) ground-motion records of select major earthquakes in California from the NGA-West2 database. Specifically, the 1966 M6.2 Parkfield, 1979 M6.5 Imperial Valley, 1984 M6.2 Morgan Hill, 1986 M6.1 North Palm Springs, 1987 M6.5 Superstition Hills, 1989 M6.9 Loma Prieta, 1992 M7.3 Landers, 1994 M6.7 Northridge, 2004 M6 Parkfield, and 2010 M7.2 El-Mayor Cucapah earthquakes are covered. Among all the events listed, the M7.2 El-Mayor Cucapah is not in the GK15 database. Our objective here is to demonstrate the performance of the GMPEs in predicting the ground motions from California regardless of whether the particular event was used in deriving the GMPE. 

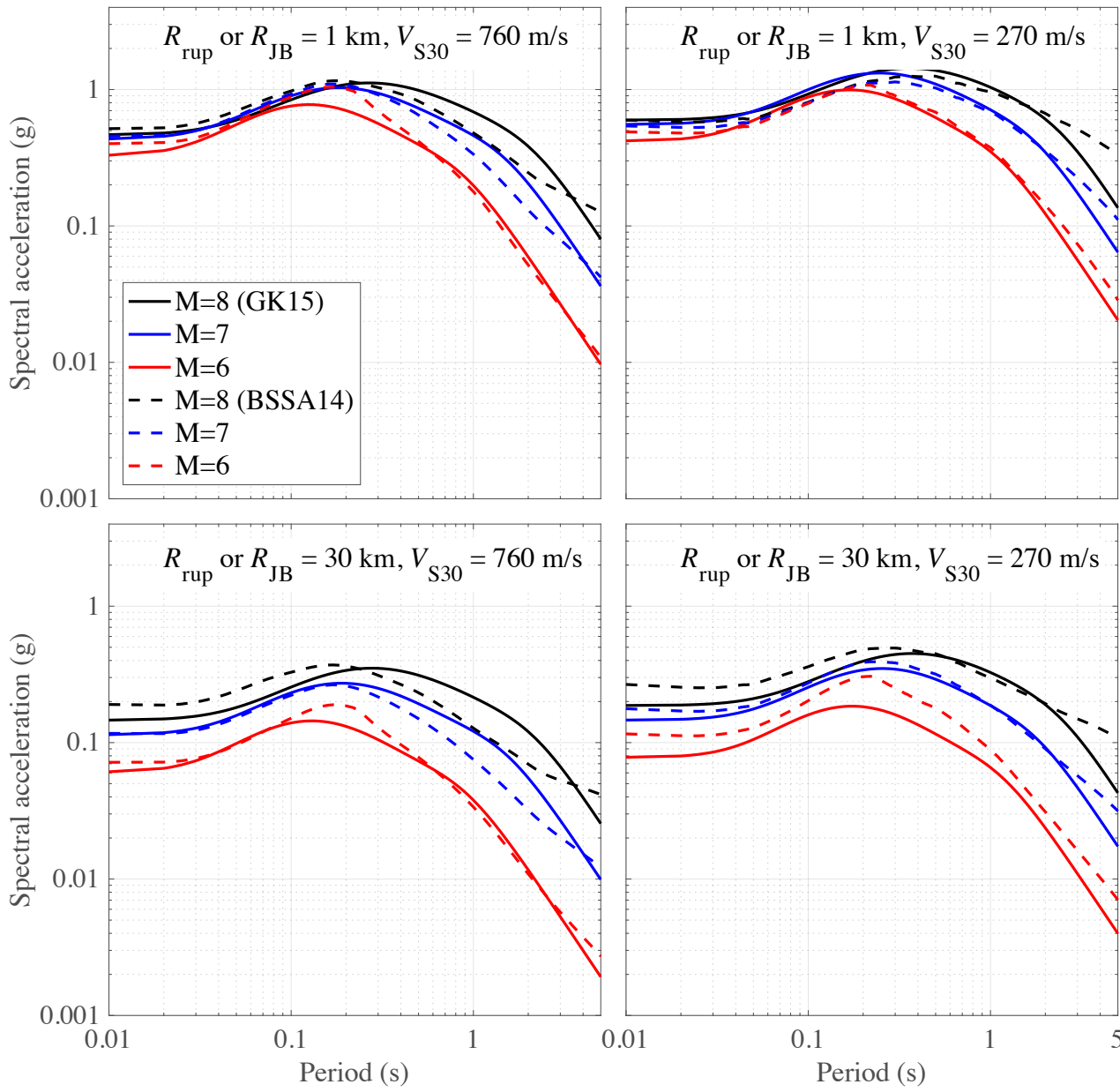

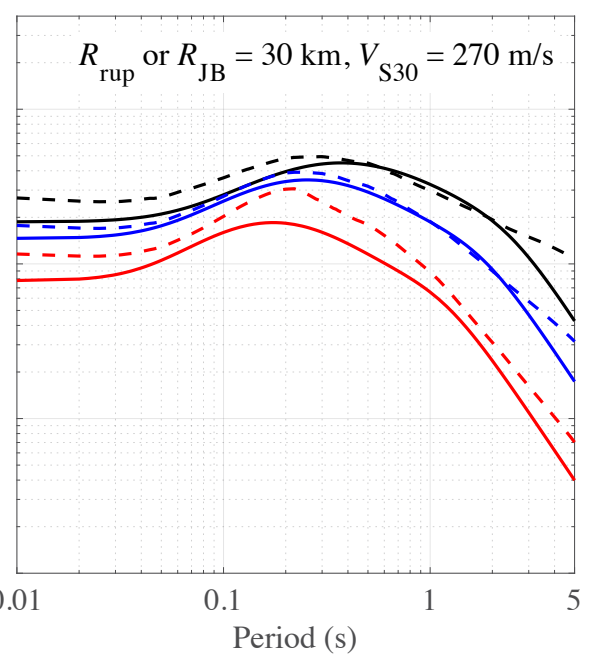

Figure 9. Plots showing a comparison of the median estimates of response-spectral shapes and amplitudes versus period (in seconds [s]) between the Graizer and Kalkan $(2015,2016)(G K 15)$ and Boore and others (2014) (BSSA14) ground-motion prediction equations for strike-slip magnitudes 6,7 , and 8 earthquakes at a rupture distance (defined as either $R_{\text {rup }}$ or $R_{\mathrm{JB}}$ ) of 1 and 30 kilometers (km). Comparisons are shown for $V_{\mathrm{s} 30}$ equal to 270 and 760 meters per second $(\mathrm{m} / \mathrm{s})$. All parameters are as defined in figure 1.

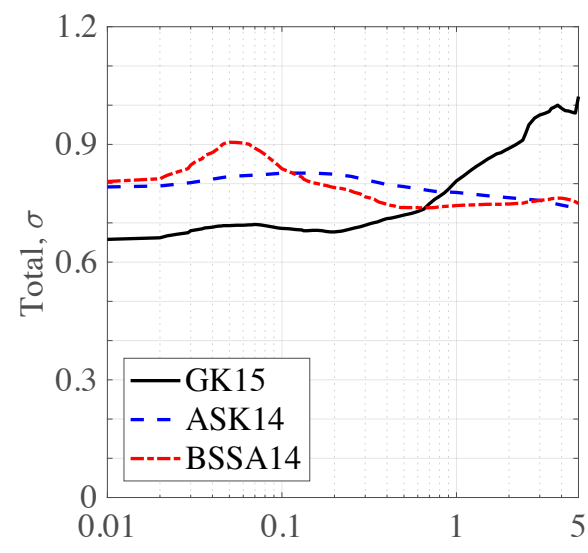

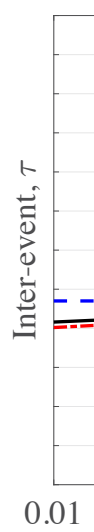

0.1

Period (s)

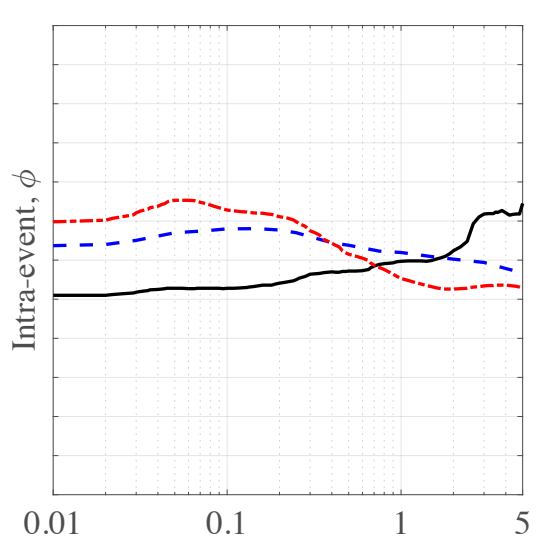

Figure 10. Plots showing a comparison of total, inter-event, and intra-event variability versus period (in seconds [s]) of the Graizer and Kalkan (2015, 2016) (GK15), Abrahamson and others (2014) (ASK14), and Boore and others (2014) (BSSA14) ground-motion prediction equations for a magnitude 5 earthquake. 

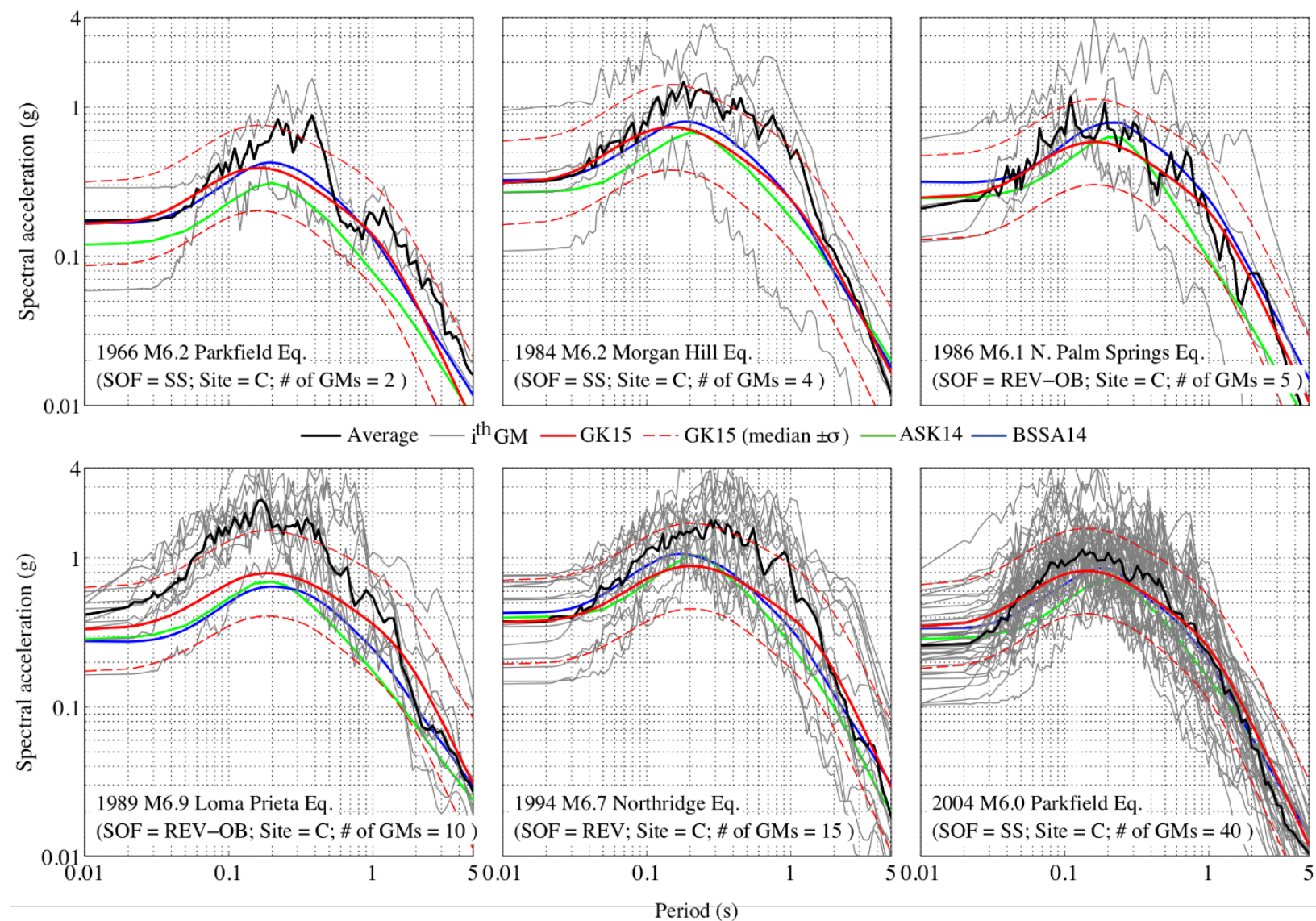

Figure 11. Plots showing a comparison of the median estimates of response-spectral shapes and amplitudes versus period (in seconds [s]) by the Graizer and Kalkan $(2015,2016)$ (GK15), Abrahamson and others (2014) (ASK14), and Boore and others (2014) (BSSA14) ground-motion prediction equations (GMPEs) with the observations from select six major Californian earthquakes from the NGA-West2 database. Ground-motion data correspond to near-field records (0-20 kilometers [km]) within National Earthquake Hazards Reduction Program site class C. Dashed curves indicate the 16th- and 84th-percentile predictions by the GK15 GMPE. Style of faulting (SOF), site class, and number of ground motions (GMs) from each earthquake are indicated. $M$, magnitude; $S S$, strike slip; REV, reverse; REV- $O B$, reverse oblique; $\sigma$, standard deviation.

In figures 11-13, the ground-motion records correspond to NEHRP site class $\mathrm{C}$ or $\mathrm{D}$. The number of records satisfying the distance and soil condition selection criteria is listed on each panel where the average spectra of records are shown by thick jagged curves and they are compared with the predictions. Individual spectra of records are also shown by thin jagged curves to demonstrate the variability. The predictions are for the average $V_{\mathrm{S} 30}$ of each ground-motion set. The 16th- and 84th-percentile predictions of GK15, shown by dashed curves, bound most of the SA data. For all near- and intermediate-field events, the GK15 GMPE yields predictions closer to the average of the observations (that is, the predicted and observed trends of the peak [period and amplitude] of the response spectra with magnitude and distance match). The width of the predicted response spectra is also comparable to the observations. Some of the variability is possibly caused by the fluctuations of the site condition within the site class. The predicted response spectra by GK15 are also close to those estimated by the other two GMPEs.
In figure 14, comparisons are shown for the strongmotion data of the 2014 M6 South Napa earthquake- the most recent damaging event in California that is not included in the NGA-West 2 database. Ground-motion data shown uses $V_{\mathrm{S} 30}$ adjusted to $760 \mathrm{~m} / \mathrm{s}$ following Seyhan and Stewart (2014). The GMPE predictions are also shown for $V_{\mathrm{S} 30}=760 \mathrm{~m} / \mathrm{s}$ to be able to compare observations directly with the attenuation curves. The 16th- and 84th-percentile predictions of the GMPEs are also shown by dashed curves. The first panel shows amplified PGA as a near-field ( 0 to $10 \mathrm{~km}$ ) bump - this phenomenon is captured by the GK15 GMPE. A more pronounced anelastic decay of the attenuation curves at about $90 \mathrm{~km}$ for GK15 as compared to figure $1 A$ is caused by lower $Q_{0}(50)$ for the Napa region, according to the range suggested by Ford and others (2008). As previously mentioned, $Q_{0}=150$ is the average for California; it could be lower or higher in certain regions. The largest PGA $(\sim 1 g)$ during this earthquake, recorded at the Carquinez Bridge, is significantly affected by local site amplification (Baltay and Boatwright, 2015). Residual plots 

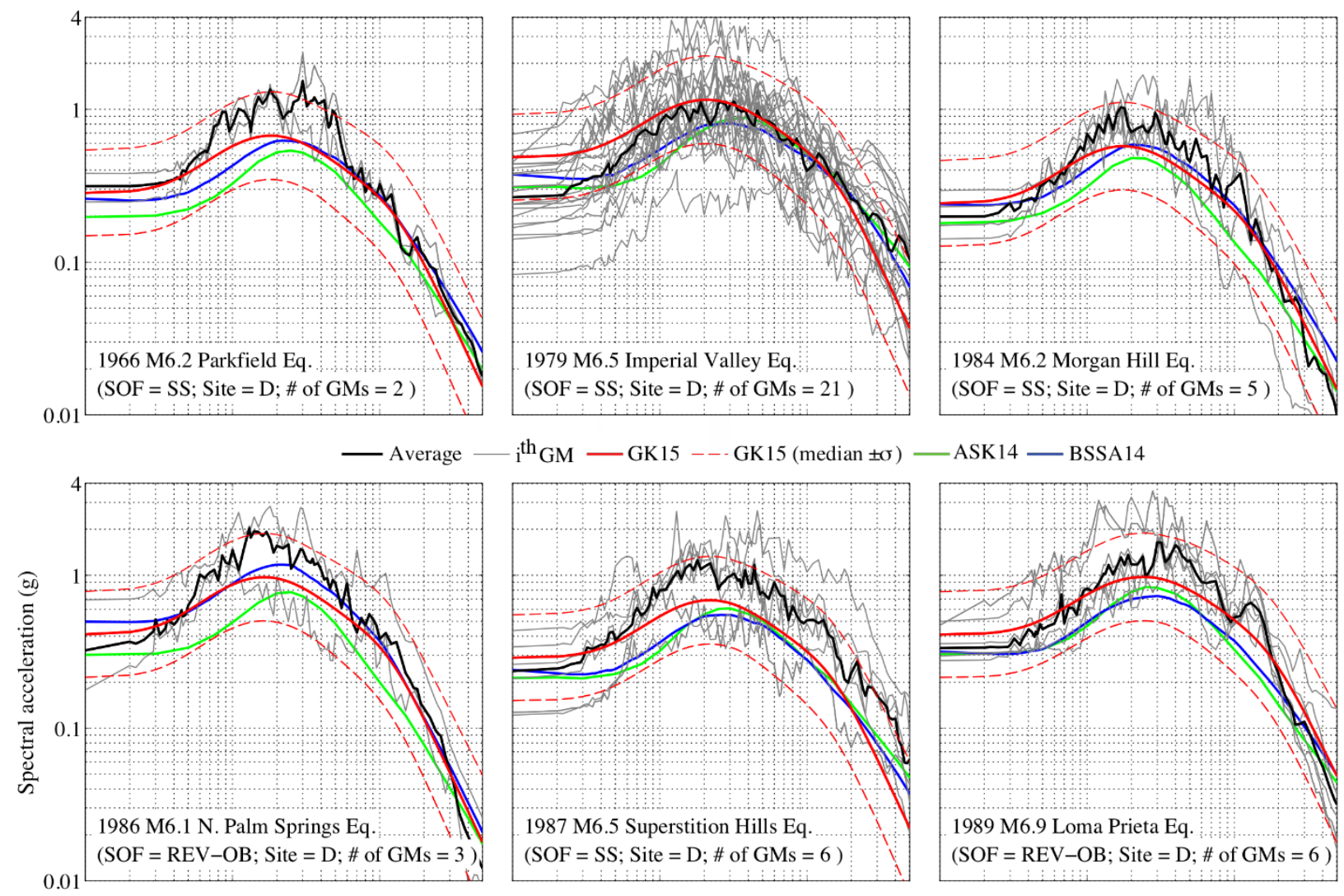

$-\mathrm{i}^{\text {th }} \mathrm{GM}-\mathrm{GK} 15--$ GK15 (median $\pm \sigma$ )

$$
\text { - ASK } 14 \text { - BSSA14 }
$$
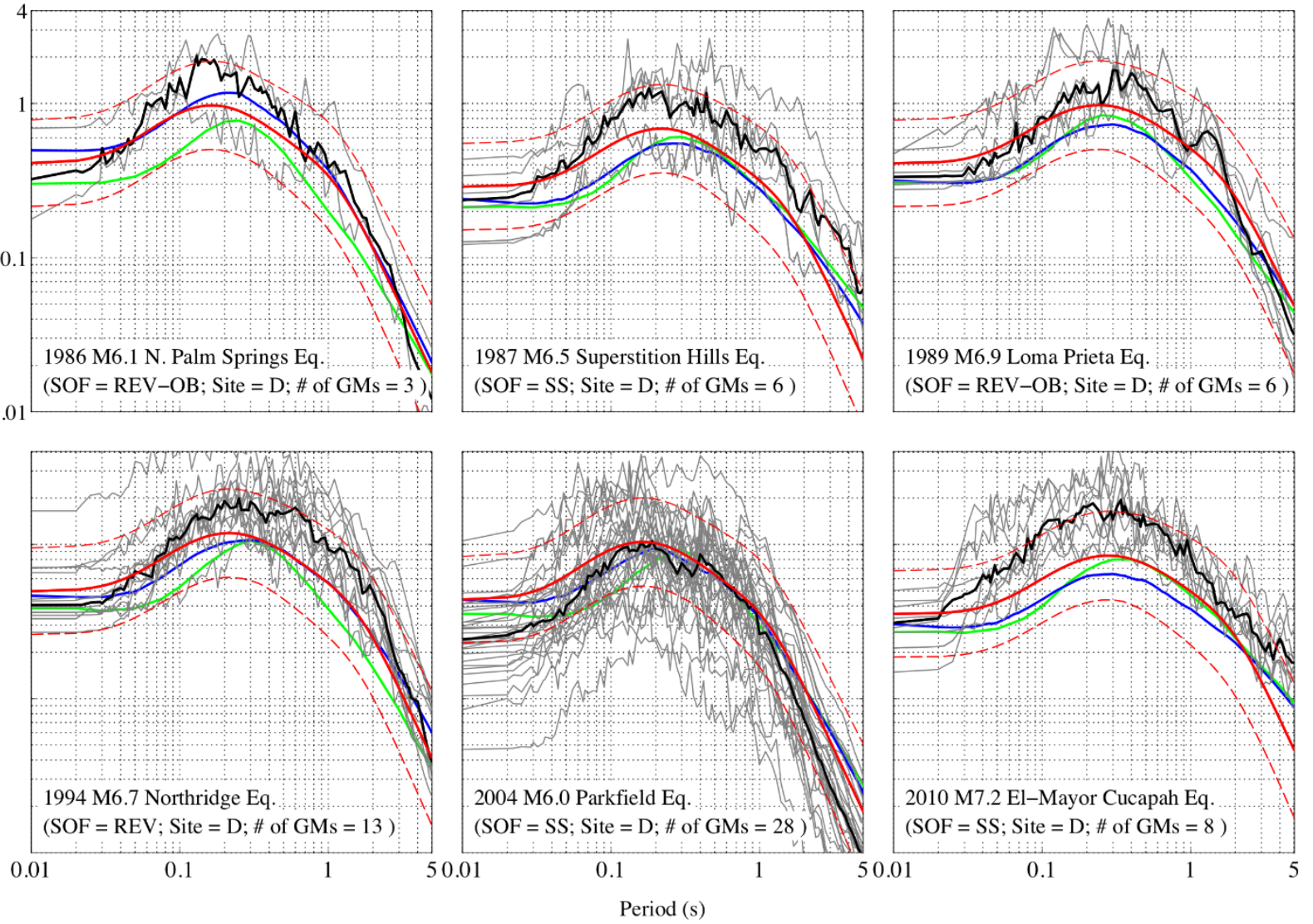

Figure 12. Plots showing a comparison of the median estimates of response-spectral shapes and amplitudes versus period (in seconds [s]) by the Graizer and Kalkan $(2015,2016)$ (GK15), Abrahamson and others (2014) (ASK14), and Boore and others (2014) (BSSA14) ground-motion prediction equations (GMPEs) with the observations from select nine major Californian earthquakes from the NGA-West2 database. Ground-motion data correspond to near-field records $(0-20$ kilometers [km]) within National Earthquake Hazards Reduction Program site class D. Dashed curves indicate the 16th- and 84th-percentile predictions by the GK15 GMPE. Style of faulting (SOF), site class, and number of ground motions (GMs) from each earthquake are indicated. $M$, magnitude; SS, strike slip; REV, reverse; REV-OB, reverse oblique; $\sigma$, standard deviation.

show a logarithmic difference between the observations and predictions. Both the ASK14 and BSSA14 GMPEs' median predictions are systematically larger than the observations.

Event term, representing approximately the mean offset of the data from predictions by the GMPE median, is used to evaluate GMPE performance (Boore and others, 2014). Based on the residuals, event terms for each intensity measure and each GMPE are listed in table 3. The GK15 GMPE has the lowest event terms. Both ASK14 and BSSA14 GMPEs have negative event terms, suggesting that the South Napa event is an earthquake with probably a much lower stress-drop than the NGA-West2 average. 

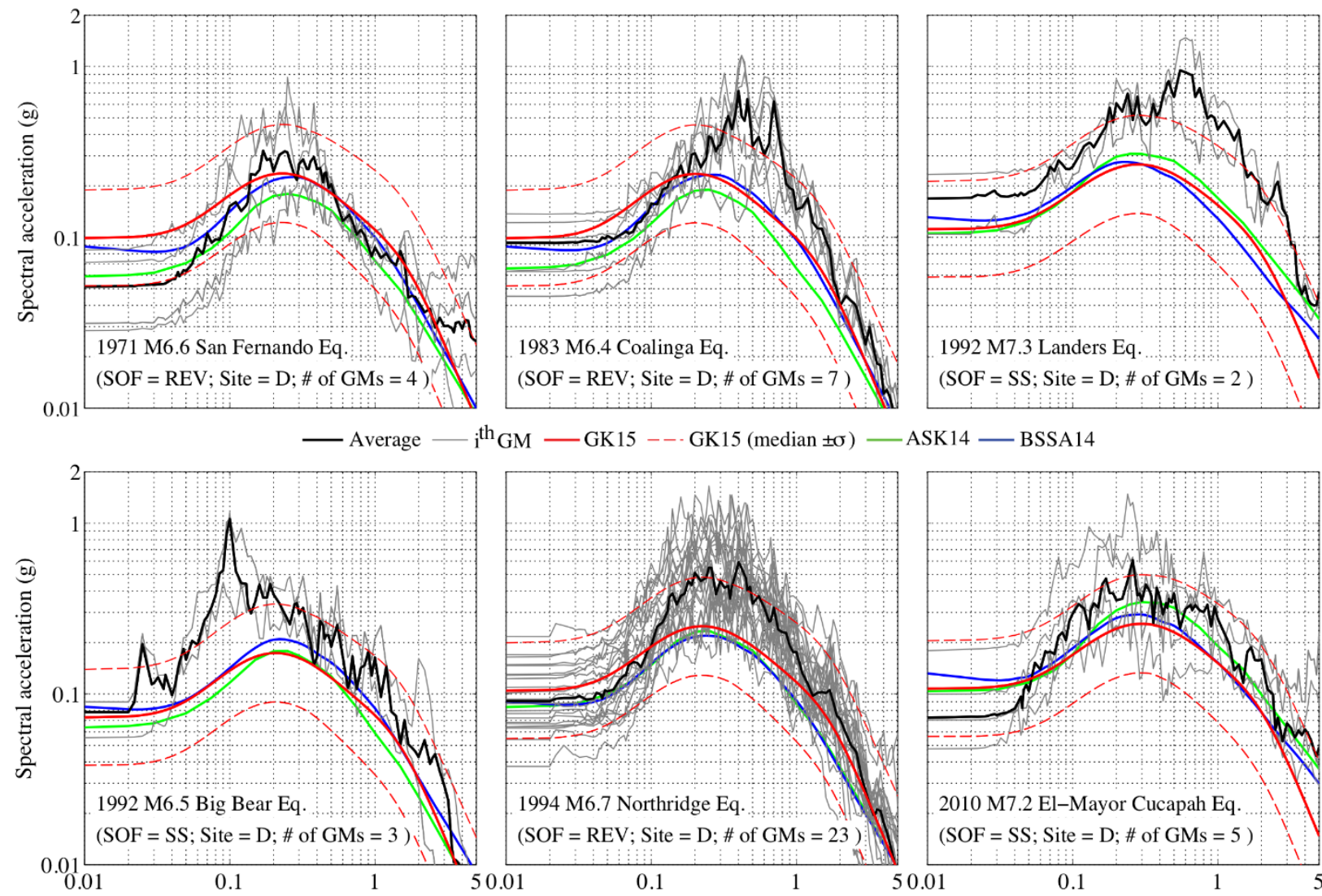

$\mathrm{i}^{\text {th }} \mathrm{GM}-\mathrm{GK} 15-\cdots \cdot \mathrm{GK} 15$ (median $\pm \sigma$

ASK 14 - BSSA14
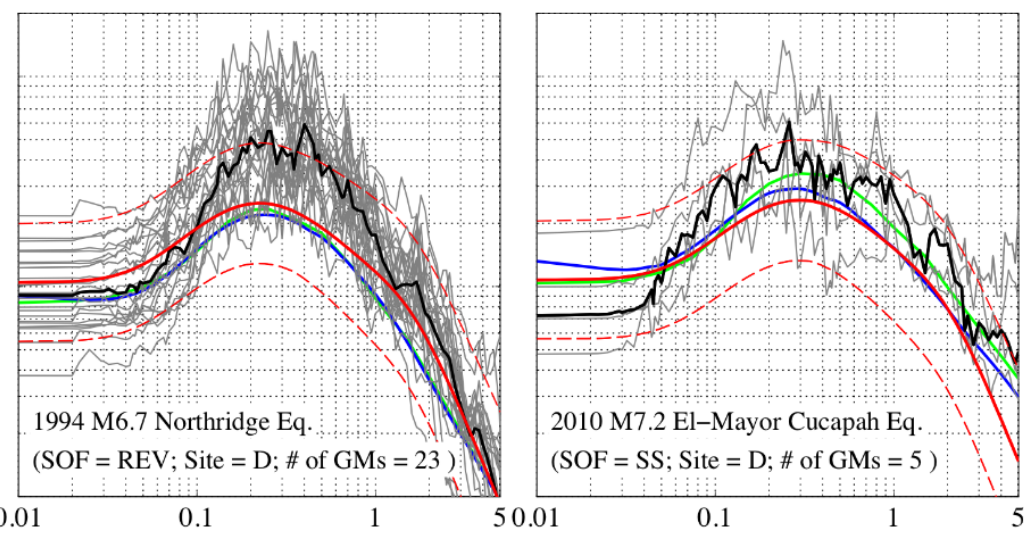

Period (s)

Figure 13. Plots showing a comparison of the median estimates of response-spectral shapes and amplitudes versus period (in seconds [s]) by the Graizer and Kalkan $(2015,2016)$ (GK15), Abrahamson and others (2014) (ASK14), and Boore and others (2014) (BSSA14) ground-motion prediction equations (GMPEs) with the observations from select six major Californian earthquakes from the NGA-West2 database. Ground-motion data correspond to intermediate-field records (50-70 kilometers [km]) within National Earthquake Hazards Reduction Program site class D. Dashed curves indicate 16th- and 84th-percentile predictions by the GK15 GMPE. Style of faulting (SOF), site class, and number of ground motions (GMs) from each earthquake are indicated. $M$, magnitude; $S S$, strike slip; $R E V$, reverse; $R E V-O B$, reverse oblique; $\sigma$, standard deviation.

Table 3. Event terms for the 2014 magnitude 6.0 South Napa earthquake for three groundmotion prediction equations.

[Ground-motion prediction equations are GK15, Graizer and Kalkan (2015, 2016); ASK14, Abrahamson and others (2014); and BSSA14, Boore and others (2014)]

\begin{tabular}{lccc}
\hline \multicolumn{1}{c}{ Event term } & GK15 & ASK14 & BSSA14 \\
\hline Peak ground acceleration & -0.180 & -0.679 & -1.185 \\
Spectral acceleration at 0.2 seconds & -0.046 & -0.703 & -1.210 \\
Spectral acceleration at 1.0 seconds & 0.124 & -0.427 & -0.876 \\
Spectral acceleration at 3.0 seconds & 0.441 & -0.377 & -0.594 \\
\hline
\end{tabular}



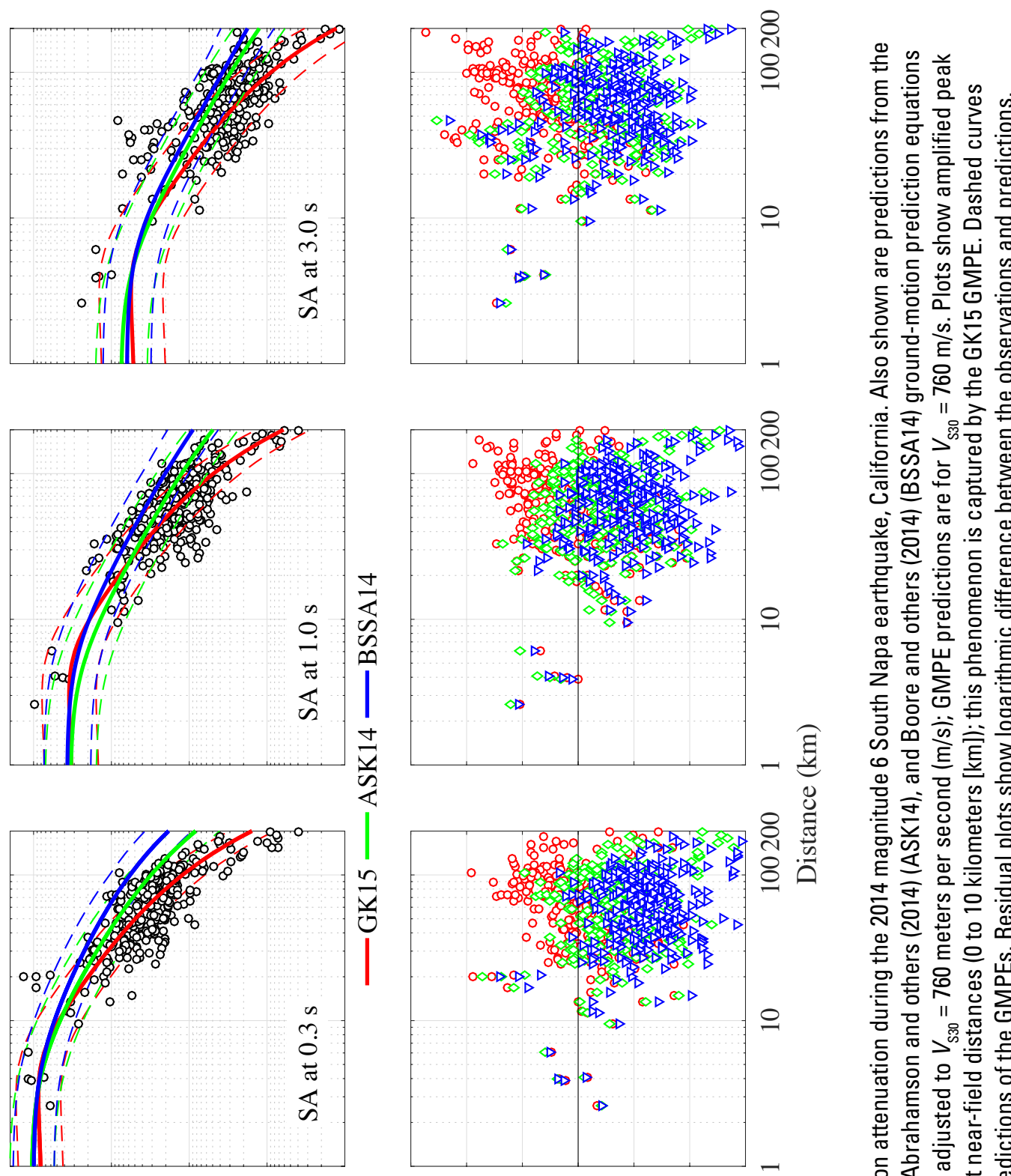

尧守"

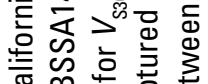

త

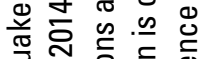

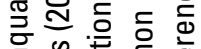

言 语

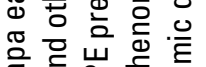

음

$\sum_{0}$

号品菂 은

๘ $\overline{\mathrm{E}} \overline{\underline{\underline{E}}}$

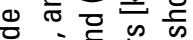

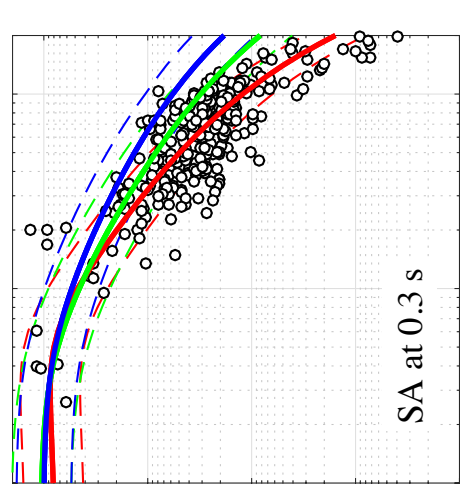

旁㐫

范起㐫

호은 흔

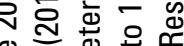

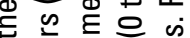

윰웜

言号

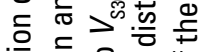

尊

ट्ट

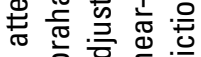

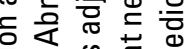

는 $\frac{\omega}{5}$ 응 弟

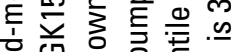

등 就

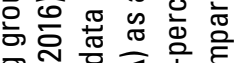

인

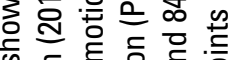

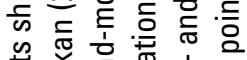

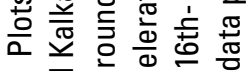

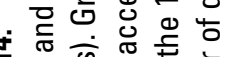

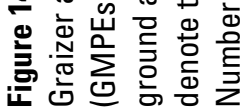

$\begin{array}{cccc}-1 & \overrightarrow{0} & \overrightarrow{0} & \overline{8} \\ & 0 & 0 & 0\end{array}$

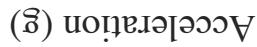

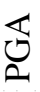

列 


\section{Stage 3: Comparisons of Residuals Using the NGA-West2 Database}

We performed mixed-effects residuals analyses in order to evaluate how well GK15, ASK14, and BSSA14 predict the near-source (within $80 \mathrm{~km}$ of the fault) subset of the NGA-West2 database and to confirm that GK15 is not biased with respect to $M$, $R_{\text {rup }}, V_{\mathrm{S} 30}$, depth to basin $\left(B_{\text {depth }}\right)$, or style-of-faulting $(F)$ parameters by examining trends of residuals against them. The distribution of data, covering 975 ground motions from 73 Californian events (listed in table 4) ranging from $M 5$ to 7.36, is displayed in figure 15 against $M, R_{\text {rup }}$, and $V_{\mathrm{S} 30}$. Histogram bar charts are also shown with NEHRP site classifications marked by varying symbols.

The residuals at PGA and SA at $0.2,1.0$, and 3.0 s spectral periods are computed as follows:

$$
\operatorname{Res}_{\mathrm{ij}}=\ln \left(Y_{\mathrm{ij}}\right)-\mu_{\mathrm{ij}}\left(M, R_{\mathrm{rup}}, V_{\mathrm{S} 30}, B_{\mathrm{depth}}, F\right),
$$
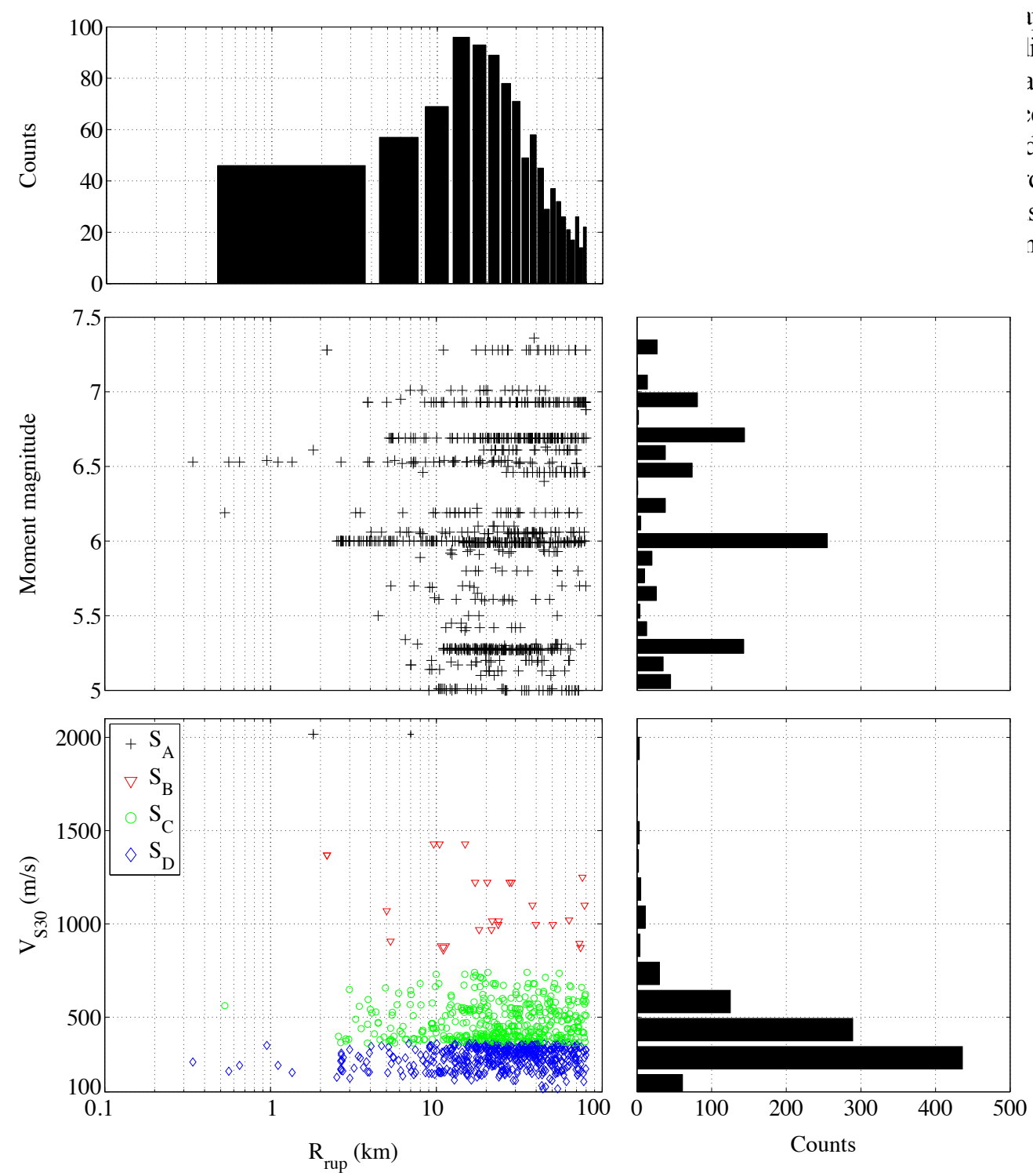

where $i$ is the event,

$\mathrm{j}$ is the recording index,

$\operatorname{Res}_{\mathrm{ij}} \quad$ is the residual of the $\mathrm{jth}$ recording of the ith event,

$Y_{\mathrm{ij}} \quad$ is the intensity measure, such as PGA or SA ordinates, from the jth recording of the ith event, and

$\mu_{\mathrm{ij}} \quad$ is the GMPE's median estimate in natural logarithmic units.

In order to separate inter-event disparities from intra-event variations, we performed a mixed-effects analysis with respect to independent predictors of $M, R_{\text {rup }}\left(R_{\mathrm{JB}}\right.$ for BSSA14), $V_{\mathrm{S} 30}$, and $B_{\text {depth }}$. We fit an intercept $a$ and slope $b$ to residuals according to the following formulation:

$$
\operatorname{Res}_{\mathrm{ij}}=a+b x_{\mathrm{i}}+\eta_{\mathrm{i}}+\varepsilon_{\mathrm{ij}},
$$

where $\quad x_{\mathrm{i}} \quad$ is the independent predictor parameter,

$\eta_{\mathrm{i}}$ is the event term (inter-event residual) for event $\mathrm{i}$, and

$\varepsilon_{\mathrm{ij}} \quad$ is the intra-event residual for recording $\mathrm{j}$ in event $i$.

Ipproximate mean offset of the lictions provided by the median of are used to evaluate the GMPE's :e predictor variables. Both event and $\mathrm{d}$ to be random Gaussian variables $\mathrm{d}$ deviations are indicated by $\tau$ and $\mathrm{s}$ of the analyses performed on the a Joyner and Boore (1993) and

Figure 15. Plots showing the distribution of the NGAWest2 near-source California earthquake events with respect to moment magnitude $(M), V_{\mathrm{s} 30}$ (in meters per second [m/s]), and $R_{\text {rup }}$ (in kilometers [km]). Near source refers to $R_{\text {rup }} \leq 80$ $\mathrm{km}$. Bar charts show histograms of data; National Earthquake Hazards Reduction Program site categories are marked by various symbols. For these events, $M \geq 5$, the number of records is 975 , and the number of events $=73$. 
Table 4. List of California earthquake events in a near-source (within 80 kilometers of the fault) subset of the NGA-West2 database.

[No., number; Calif or CA, California; N., North]

\begin{tabular}{|c|c|c|c|c|c|c|c|}
\hline No. & Year & Event name & $\begin{array}{c}\text { Moment } \\
\text { magnitude }\end{array}$ & No. & Year & Event name & $\begin{array}{c}\text { Moment } \\
\text { magnitude }\end{array}$ \\
\hline 1 & 1937 & Humbolt Bay & 5.80 & 38 & 1980 & Mammoth Lakes-02 & 5.69 \\
\hline 2 & 1938 & Imperial Valley-01 & 5.00 & 39 & 1980 & Mammoth Lakes-03 & 5.91 \\
\hline 3 & 1938 & Northwest Calif-01 & 5.50 & 40 & 1980 & Mammoth Lakes-04 & 5.70 \\
\hline 4 & 1940 & Imperial Valley-02 & 6.95 & 41 & 1980 & Mammoth Lakes-05 & 5.70 \\
\hline 5 & 1941 & Northern Calif-01 & 6.40 & 42 & 1980 & Mammoth Lakes-06 & 5.94 \\
\hline 6 & 1942 & Borrego & 6.50 & 43 & 1983 & Mammoth Lakes-10 & 5.34 \\
\hline 7 & 1951 & Imperial Valley-03 & 5.60 & 44 & 1983 & Mammoth Lakes-11 & 5.31 \\
\hline 8 & 1951 & Northwest Calif-03 & 5.80 & 45 & 1983 & Borah Peak, ID-01 & 6.88 \\
\hline 9 & 1952 & Kern County & 7.36 & 46 & 1983 & Borah Peak, ID-02 & 5.10 \\
\hline 10 & 1952 & Northern Calif-02 & 5.20 & 47 & 1984 & Morgan Hill & 6.19 \\
\hline 11 & 1952 & Southern Calif & 6.00 & 48 & 1984 & Bishop (Round Valley) & 5.82 \\
\hline 12 & 1953 & Imperial Valley-04 & 5.50 & 49 & 1986 & Hollister-04 & 5.45 \\
\hline 13 & 1954 & Central Calif-01 & 5.30 & 50 & 1986 & N. Palm Springs & 6.06 \\
\hline 14 & 1954 & Northern Calif-03 & 6.50 & 51 & 1987 & Baja California & 5.50 \\
\hline 15 & 1955 & Imperial Valley-05 & 5.40 & 52 & 1987 & Whittier Narrows-01 & 5.99 \\
\hline 16 & 1957 & San Francisco & 5.28 & 53 & 1987 & Whittier Narrows-02 & 5.27 \\
\hline 17 & 1960 & Central Calif-02 & 5.00 & 54 & 1987 & Superstition Hills-01 & 6.22 \\
\hline 18 & 1960 & Northern Calif-04 & 5.70 & 55 & 1987 & Superstition Hills-02 & 6.54 \\
\hline 19 & 1961 & Hollister-01 & 5.60 & 56 & 1989 & Loma Prieta & 6.93 \\
\hline 20 & 1961 & Hollister-02 & 5.50 & 57 & 1992 & Cape Mendocino & 7.01 \\
\hline 21 & 1966 & Parkfield & 6.19 & 58 & 1992 & Landers & 7.28 \\
\hline 22 & 1967 & Northern Calif-05 & 5.60 & 59 & 1992 & Big Bear-01 & 6.46 \\
\hline 23 & 1967 & Northern Calif-06 & 5.20 & 60 & 1994 & Northridge-01 & 6.69 \\
\hline 24 & 1968 & Borrego Mtn & 6.63 & 61 & 1991 & Sierra Madre & 5.61 \\
\hline 25 & 1971 & San Fernando & 6.61 & 62 & 1992 & Joshua Tree, CA & 6.10 \\
\hline 26 & 1973 & Point Mugu & 5.65 & 63 & 1994 & Northridge- 02 & 6.05 \\
\hline 27 & 1974 & Hollister- 03 & 5.14 & 64 & 1994 & Northridge- 03 & 5.20 \\
\hline 28 & 1975 & Northern Calif-07 & 5.20 & 65 & 1994 & Northridge-04 & 5.93 \\
\hline 29 & 1975 & Oroville-01 & 5.89 & 66 & 1994 & Northridge- 05 & 5.13 \\
\hline 30 & 1978 & Santa Barbara & 5.92 & 67 & 1994 & Northridge-06 & 5.28 \\
\hline 31 & 1979 & Imperial Valley-06 & 6.53 & 68 & 1998 & San Juan Bautista & 5.17 \\
\hline 32 & 1979 & Imperial Valley-07 & 5.01 & 69 & 2000 & Yountville & 5.00 \\
\hline 33 & 1979 & Imperial Valley-08 & 5.62 & 70 & 2001 & Gulf of California & 5.70 \\
\hline 34 & 1980 & Livermore-01 & 5.80 & 71 & 2002 & CA/Baja Border Area & 5.31 \\
\hline 35 & 1980 & Livermore-02 & 5.42 & 72 & 2003 & San Simeon, CA & 6.50 \\
\hline 36 & 1980 & Anza (Horse Canyon)-01 & 5.19 & 73 & 2004 & Parkfield-02, CA & 6.00 \\
\hline
\end{tabular}


Intra-Event Residuals Analysis of Path, Site, and Basin-Depth Effects

The intra-event residuals $\left(\varepsilon_{\mathrm{ij}}\right)$ are used to test the GK15 GMPE with respect to distance, site effects, and basin depth. In figure 16, the intra-event residuals are plotted in natural logarithmic units for PGA and other intensity measures against $R_{\text {rup }}(0$ to $80 \mathrm{~km})$ with means and standard errors shown within bins. The bin sizes were adjusted so that each bin has approximately the same number of data points. The maximumlikelihood line is dashed, and its intercept $(a)$ and slope $(b)$ are provided on top of each plot in order to check for systematic bias with respect to the independent predictors. Although the data are slightly overpredicted at $3.0 \mathrm{~s}$ for distances between 50 and $60 \mathrm{~km}$, the results generally show no perceptible trend within the body of a predictor, indicating that the path-scaling
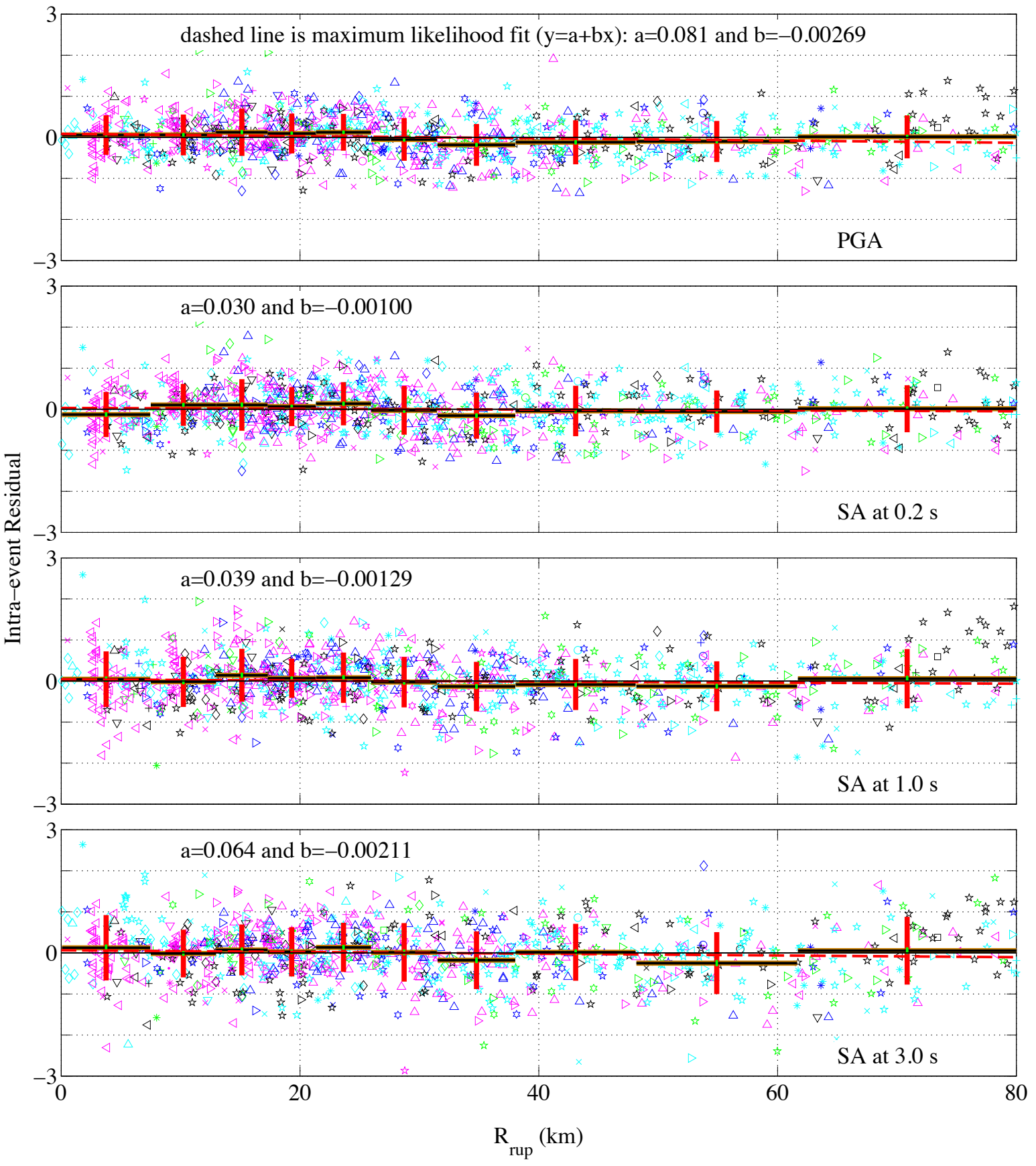

Figure 16. Plots showing the distribution of intra-event residuals in natural logarithmic units for peak ground acceleration (PGA) and spectral acceleration (SA) at 0.2, 1.0, and 3.0 seconds (s) with respect to $R_{\text {rup }}$ (in kilometers $[\mathrm{km}])$. Solid horizontal lines indicate the size of the bins and their mean value, vertical solid lines show their standard deviation, dashed lines denote a maximum-likelihood fit to residuals, and different symbols indicate different events. Note that $a$ and $b$ are intercept and slope of the maximum-likelihood fit, respectively. 
functions in GK15 reasonably represent the data trends. In similar plots in figures 17 and 18 for $V_{\mathrm{S} 30}$ and $B_{\text {depth }}$, the flatness of the trends indicates that our linear site response function (applicable for $V_{\mathrm{S} 30} \geq 200 \mathrm{~m} / \mathrm{s}$ ) is a reasonable average for California and there is little dependence (underprediction) on $B_{\text {depth }}$ between 200 and 300 meters $(\mathrm{m})$ at 1.0 and $3.0 \mathrm{~s}$.

In table 5, we compare $a$ and $b$ values of the maximum-likelihood fit to intra-event residuals and distance for the GK15, ASK14, and BSSA14 GMPEs. In general, the GMPEs have similar intercept and slope values. Neither GMPE has the lowest $a$ and $b$ values for all intensity measures, which emphasizes the need to include a variety of GMPEs in seismic hazard analysis in order to capture the epistemic uncertainty (Al Atik and Youngs, 2014; Petersen and others, 2014; Bommer and Scherbaum, 2008).

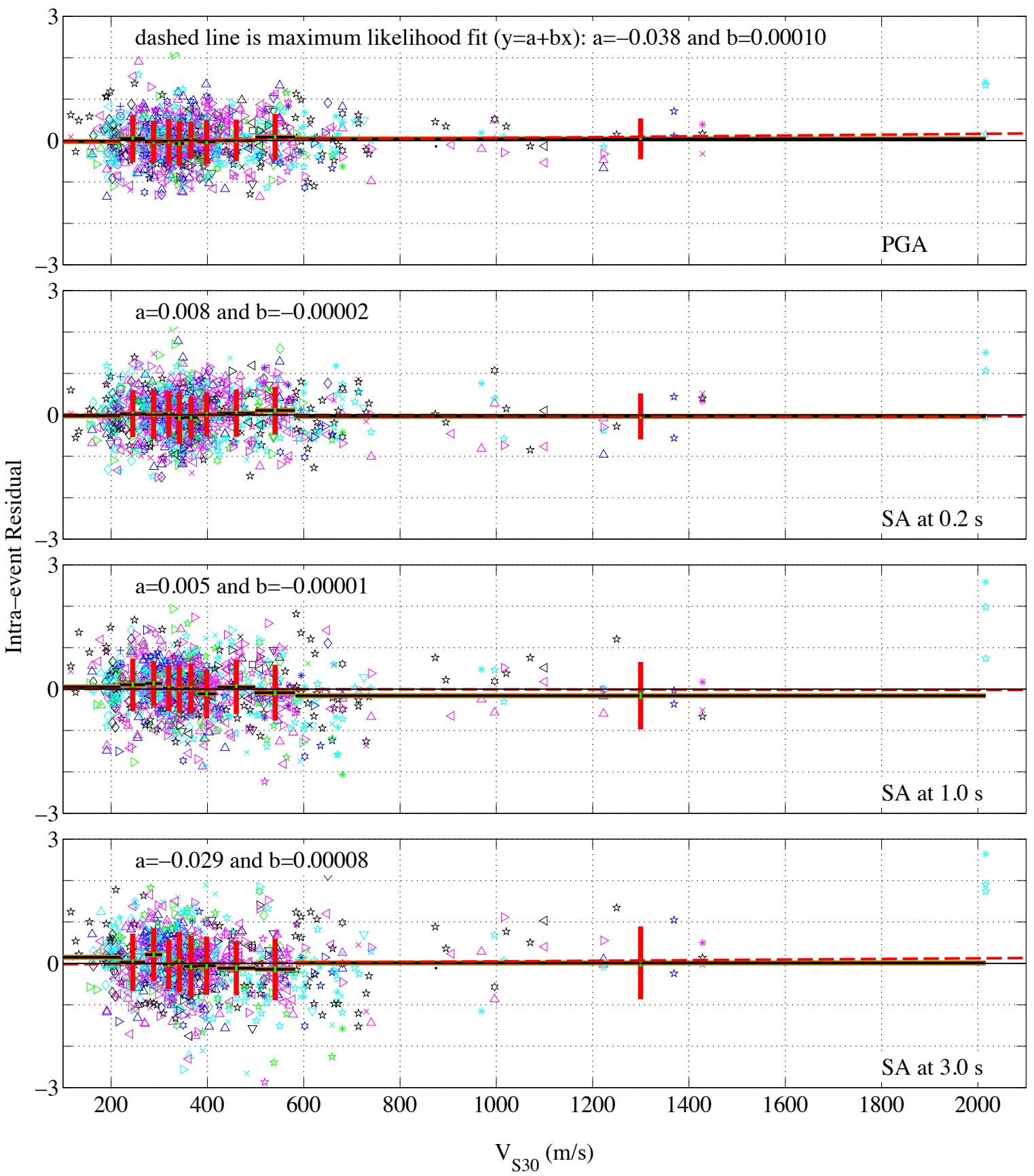

Figure 17. Plots showing the distribution of intra-event residuals in natural logarithmic units for peak ground acceleration (PGA) and spectral acceleration (SA) at 0.2, 1.0, and 3.0 seconds (s) with respect to $V_{\text {s30 }}$ (in meters per second $[\mathrm{m} / \mathrm{s}]$ ). Solid horizontal lines indicate the size of the bins and their mean value, vertical solid lines show their standard deviation, dashed lines denote a maximum-likelihood fit to residuals, and different symbols indicate different events. Note that $a$ and $b$ are intercept and slope of the maximum-likelihood fit, respectively. 
Table 5. Maximum-likelihood fit to intra-event residuals and distance for three ground-motion prediction equations.

[Ground-motion prediction equations are GK15, Graizer and Kalkan (2015, 2016); ASK14, Abrahamson and others (2014); and BSSA14, Boore and others (2014). Data consist of NGA-West2 California events ( $R_{\mathrm{rup}}$ or $R_{\mathrm{JB}} \leq 80$ kilometers, magnitude $\geq 5$ ). Number of records is 975 ; number of events is 73 . See table 4 for list of events]

\begin{tabular}{|c|c|c|c|c|c|c|}
\hline \multirow{2}{*}{ Intensity measure } & \multicolumn{3}{|c|}{ Intercept (a) } & \multicolumn{3}{|c|}{ Slope $(b)$} \\
\hline & GK15 & ASK14 & BSSA14 & GK15 & ASK14 & BSSA14 \\
\hline Peak ground acceleration & 0.081 & -0.011 & 0.020 & -0.00269 & 0.00037 & 0.00073 \\
\hline Spectral acceleration at 0.2 seconds & 0.030 & -0.046 & 0.001 & -0.00100 & 0.00154 & 0.00002 \\
\hline Spectral acceleration at 1.0 seconds & 0.039 & -0.009 & -0.015 & -0.00129 & 0.00030 & 0.00055 \\
\hline Spectral acceleration at 3.0 seconds & 0.064 & -0.003 & -0.016 & 0.00211 & 0.00009 & 0.00058 \\
\hline
\end{tabular}
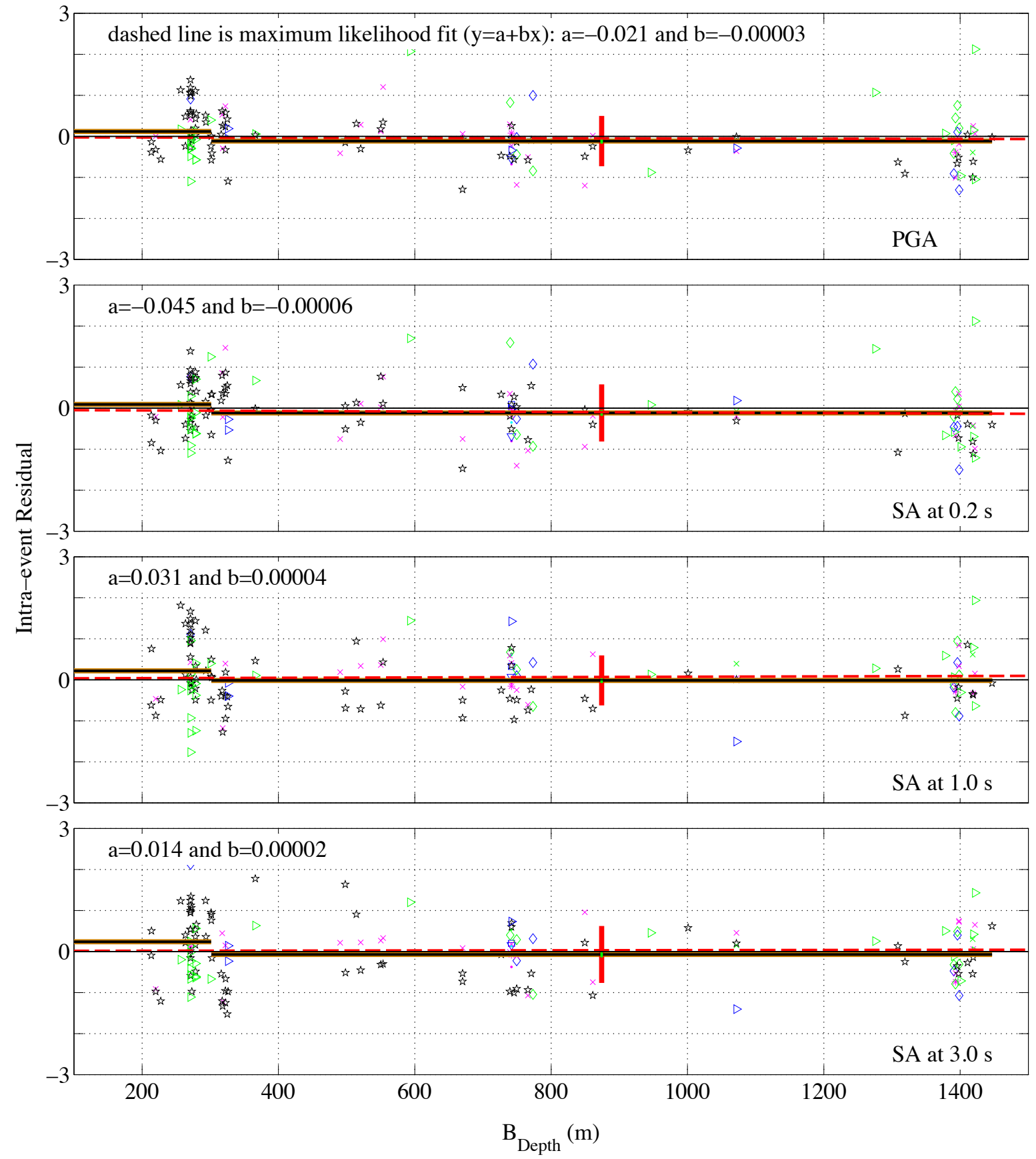

Figure 18. Plots showing the distribution of intra-event residuals in natural logarithmic units for peak ground acceleration (PGA) and spectral acceleration $(\mathrm{SA})$ at $0.2,1.0$, and 3.0 seconds (s) with respect to $B_{\text {depth }}$ (in meters [m]). Solid horizontal lines indicate the size of the bins and their mean value, vertical solid lines show their standard deviation, dashed lines denote a maximumlikelihood fit to residuals, and different symbols indicate different events. Note that $a$ and $b$ are intercept and slope of the maximum-likelihood fit, respectively. 


\section{Analysis of Source Effects Using Inter-Event Residuals}

In figures 19 and 20, event terms $\left(\eta_{\mathrm{i}}\right)$ are plotted respectively against magnitude in the range $5 \leq M \leq 7.9$ and the style of faulting parameter $(F)$ considering PGA and SA at $0.2,1.0$, and $3.0 \mathrm{~s}$. The GK15 GMPE magnitude-scaling function captures the trends from various events as evident by the near-zero intercept and near-zero slope for the magnitude of the maximum-likelihood fit, indicating that there is no significant trend with this parameter or a notable offset from zero. For the style-of-faulting parameter, near-zero slope for PGA and SA at $0.2 \mathrm{~s}$ indicates negligible dependence and no systematic bias in the residuals from GK15. Slope values smaller than -1.0 for SA at 1.0 and $3.0 \mathrm{~s}$ signify that data are slightly overpredicted, which is attributed to the limited number of events with reverse faulting mechanisms.

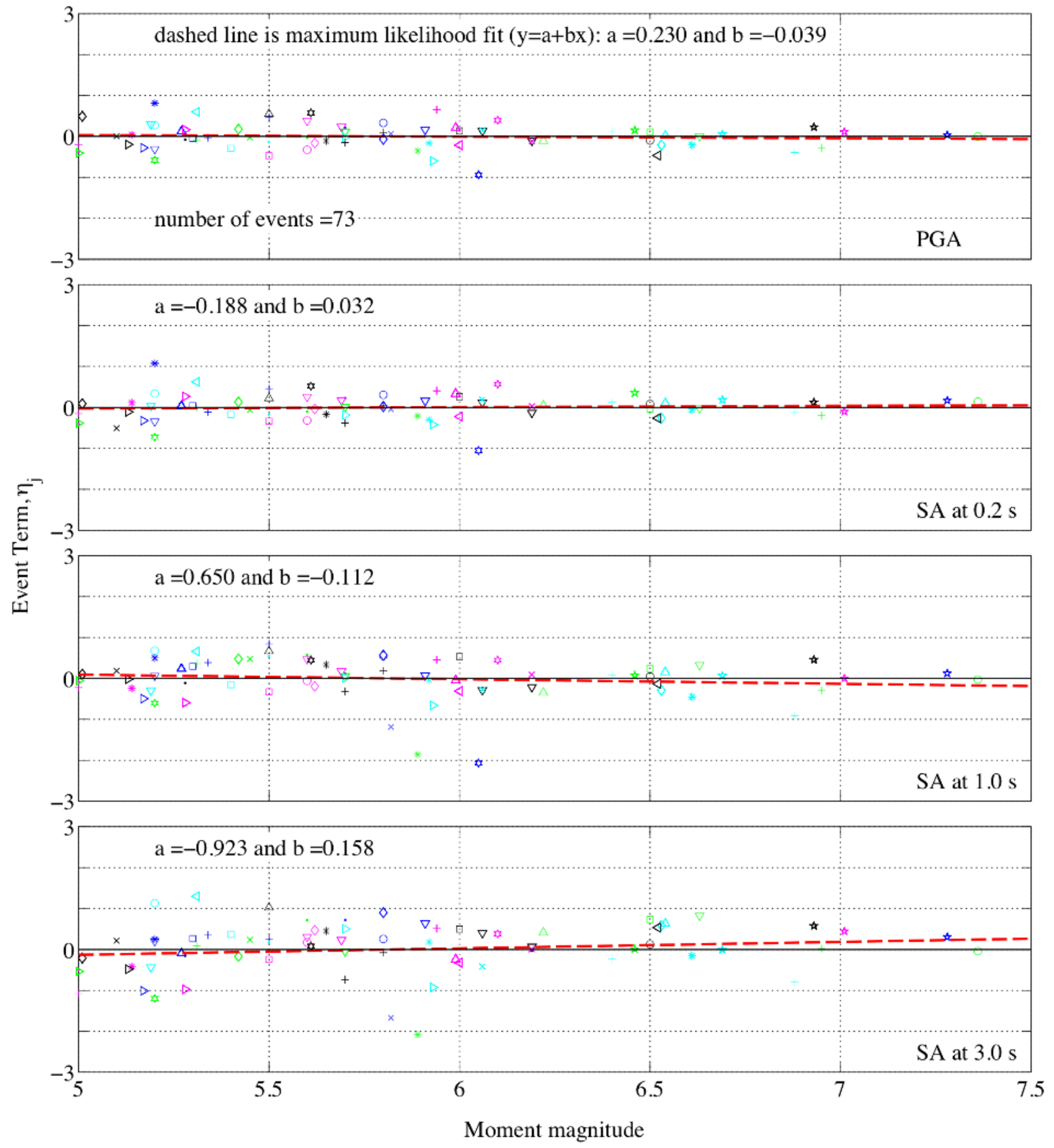

Figure 19. Plots showing the distribution of event terms $\left(\eta_{\mathrm{i}}\right)$ in natural logarithmic units for peak ground acceleration (PGA) and spectral acceleration (SA) at $0.2,1.0$, and 3.0 seconds (s) with respect to moment magnitude. In each plot, the dashed line indicates a maximum-likelihood fit to all event terms; its slope (a) and intercept $(b)$ are provided at the top of each plot. 

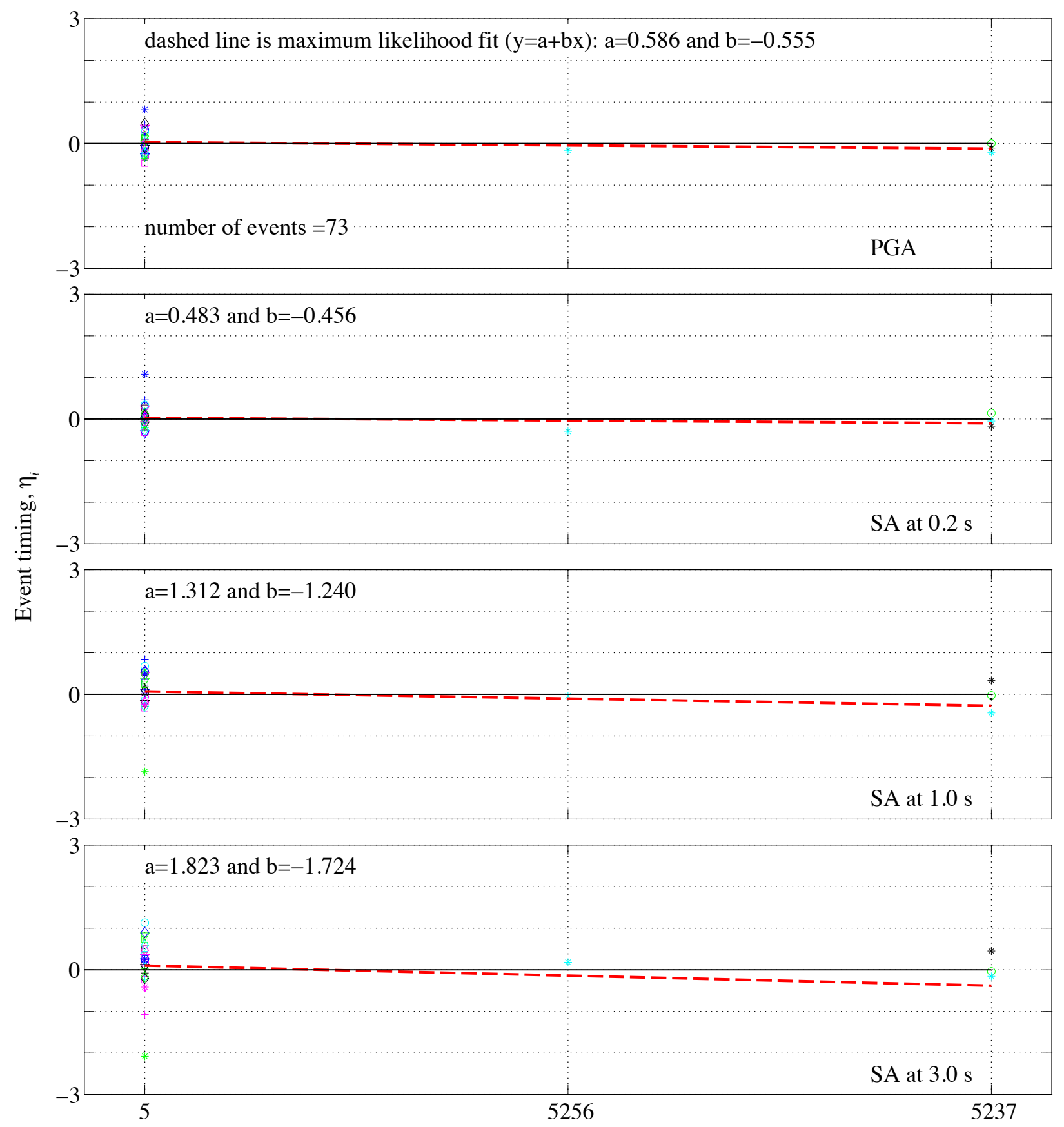

Style of faulting, $F$

Figure 20. Plots showing the distribution of event terms $\left(\eta_{\mathrm{i}}\right)$ in natural logarithmic units for peak ground acceleration (PGA) and spectral acceleration (SA) at $0.2,1.0$, and 3.0 seconds (s) with respect to style-of-faulting parameter $F$. In each plot, the dashed line indicates a maximum-likelihood fit to all event terms; its slope $(a)$ and intercept $(b)$ are provided at the top of each plot. 
In table 6, we compare $a$ and $b$ values of the maximumlikelihood fit to inter-event residuals and moment magnitude. In general, the GMPEs result in similar results. GK15 yields the lowest values of $a$ and $b$ for PGA. For SA at $0.2 \mathrm{~s}$, BSSA 14 and GK15 produce similar $a$ and $b$, which are smaller than those of ASK14. For SA at $1.0 \mathrm{~s}$, the intercept and slope are the smallest for ASK14, in between for GK15, and largest for BSSA14. For 3.0 s, BSSA14 has the lowest values of $a$ and $b$.

\section{Standard Deviations}

Table 7 compares the standard deviations of residuals among three GMPEs. The values are computed for four intensity measures considering the near-source California subset of the NGA-West2 database (see table 4). All standard deviations are in natural logarithmic units. The terms of standard deviations including inter event, intra event, and the total are very similar among the three GMPEs and their values increase with spectral period. These results underline that the GK15 GMPE does not always have the lowest standard deviations.

\section{Conclusions}

We systematically compared the GMPE of Graizer and Kalkan (2015, 2016) (GK15) with the NGA-West2 GMPEs of Abrahamson and others (2014) (ASK14) and Boore and others (2014) (BSSA14) to evaluate the similarities and differences among them. The comparisons were conducted in terms of median predictions, standard deviations, and analyses of total residuals with respect to near-field (within $20 \mathrm{~km}$ of the fault) and intermediate-field (50 to $70 \mathrm{~km}$ from the fault) ground motions from major earthquakes in California. We also used a subset of the NGA-West 2 database, including 975 ground motions within $80 \mathrm{~km}$ of the fault from 73 Californian events ranging from $M 5$ to 7.36 in order to compare intra- and inter-event residuals among the GMPEs. The key findings of this study are as follows:

1. The GK15, ASK14, and BSSA14 GMPEs demonstrate median ground-motion estimates for California generally within a factor of $1.5-2$ for $M 5-7$ events. The largest differences are for very large magnitude events with no or sparse data and for small magnitude events at long

Table 6. Maximum-likelihood fit to inter-event residuals and moment magnitude for three ground-motion prediction equations.

[Ground-motion prediction equations are GK15, Graizer and Kalkan (2015, 2016); ASK14, Abrahamson and others (2014); and BSSA14, Boore and others (2014). Data consist of NGA-West2 California events $\left(R_{\mathrm{rup}}\right.$ or $R_{\mathrm{JB}} \leq 80$ kilometers, magnitude $\geq 5$ ). Number of records is 975 ; number of events is 73 . See table 4 for list of events]

\begin{tabular}{|c|c|c|c|c|c|c|}
\hline \multirow{2}{*}{ Intensity measure } & \multicolumn{3}{|c|}{ Intercept (a) } & \multicolumn{3}{|c|}{ Slope (b) } \\
\hline & GK15 & ASK14 & BSSA14 & GK15 & ASK14 & BSSA14 \\
\hline Peak ground acceleration & 0.230 & -0.505 & -0.271 & -0.039 & 0.087 & 0.047 \\
\hline Spectral acceleration at 0.2 seconds & -0.188 & -0.992 & -0.182 & 0.032 & 0.170 & 0.031 \\
\hline Spectral acceleration at 1.0 seconds & 0.650 & 0.244 & 1.129 & -0.112 & -0.042 & -0.194 \\
\hline Spectral acceleration at 3.0 seconds & -0.923 & -0.995 & 0.276 & 0.158 & 0.171 & -0.047 \\
\hline
\end{tabular}

Table 7. Standard deviations of residuals in natural logarithmic units for three ground-motion prediction equations for near-source California earthquake events.

[Ground-motion prediction equations are GK15, Graizer and Kalkan (2015, 2016); ASK14, Abrahamson and others (2014); and BSSA14, Boore and others (2014). Data consist of NGA-West2 California events ( $\mathrm{R}_{\mathrm{rup}}$ or $R_{\mathrm{JB}} \leq 80$ kilometers, magnitude $\geq 5$ ). Number of records is 975 ; number of events is 73 . See table 4 for list of events]

\begin{tabular}{|c|c|c|c|c|c|c|c|c|c|}
\hline \multirow{2}{*}{ Intensity measure } & \multicolumn{3}{|c|}{ Inter event $(\tau)$} & \multicolumn{3}{|c|}{ Intra event $(\phi)$} & \multicolumn{3}{|c|}{ Total $(\sigma)$} \\
\hline & GK15 & ASK14 & BSSA14 & GK15 & ASK14 & BSSA14 & GK15 & ASK14 & BSSA14 \\
\hline Peak ground acceleration & 0.425 & 0.420 & 0.377 & 0.519 & 0.546 & 0.529 & 0.670 & 0.688 & 0.649 \\
\hline Spectral acceleration at 0.2 seconds & 0.440 & 0.465 & 0.415 & 0.576 & 0.599 & 0.568 & 0.725 & 0.758 & 0.703 \\
\hline Spectral acceleration at 3.0 seconds & 0.842 & 1.091 & 0.818 & 0.710 & 0.908 & 0.691 & 1.101 & 1.419 & 1.071 \\
\hline
\end{tabular}


distances. To account for the variable density of data in different magnitude and distance bins, Petersen and others (2014) introduced additional epistemic uncertainty terms for hazard computations.

2. The GK15 GMPE produces similar or slightly smaller ground motions at very close distances to the fault (within $\sim 5 \mathrm{~km}$ ) and at distances of more than $20 \mathrm{~km}$ from the fault for earthquakes with magnitude larger than 6 . Between 5 and $20 \mathrm{~km}$ from the fault, the GK15 GMPE results in higher estimates of ground motion than either the ASK14 or BSSA14 GMPE does. The distance scaling of the GMPEs shows some differences, which stem from different functional forms used for distance scaling and the different datasets used for constraining the estimation coefficients of each GMPE.

3. An additional difference between the GK15 GMPE and the other two GMPEs that was not directly assessed in the comparisons, but is essential, is related to the inclusion of a quality factor $\left(Q_{0}\right)$. The GK15 GMPE's use of a $Q_{0}$ that can be changed to suit the region of interest is an improvement over other GMPEs. On the other hand, GK15 neither includes nonlinear-site response nor hanging-wall effect parameters.

4. The standard deviations of original GMPEs are different. At periods less than $0.7 \mathrm{~s}$, the GK15 GMPE offers lower standard deviations than the ASK14 and BSSA14 GMPEs do. At longer periods ( $>1.0 \mathrm{~s}$ ), the standard deviations of other GMPEs are smaller than those of the GK15 GMPE. When the subset of the NGA-West2 database is considered, the terms of standard deviations (total, intra event, and inter event) among the three GMPEs become similar; for instance, total standard deviation for the three GMPEs is between 0.65 and 0.69 for PGA, 0.7 and 0.76 for SA at $0.2 \mathrm{~s}, 0.89$ and 1.07 for SA at $1.0 \mathrm{~s}$, and 1.07 and 1.42 for SA at $3.0 \mathrm{~s}$.

5. The analysis of mixed-effects residuals based on the subset of the NGA-West2 database reveals that the GK15 GMPE is generally unbiased with respect to its independent predictors, including moment magnitude, closest distance to fault, $V_{\mathrm{S} 30}$, style of faulting, and basin depth.

\section{Data and Resources}

The Graizer and Kalkan $(2015,2016)$ ground-motion prediction equation (GMPE) is available for MATLAB and Excel at https://earthquake.usgs.gov/research/software/\#gmpe (last accessed on March 1, 2019). A summary (flat-file) of the NGA-West2 database is available as an Excel spreadsheet at http://peer.berkeley.edu/ngawest2/databases/ (last accessed on March 1, 2019). The additional Californian events used in development of the Graizer and Kalkan $(2015,2016)$ GMPE are available at https://www.strongmotioncenter.org/ (last accessed on March 1, 2019).

\section{References Cited}

Abrahamson, N.A., Silva, W.J. and Kamai, R., 2014, Summary of the ASK14 Ground Motion Relation for Active Crustal Regions: Earthquake Spectra, v. 30, no. 3, p. 1025-1055.

Al Atik, L., and Youngs, R.R., 2014, Epistemic uncertainty for NGA-West2 models: Earthquake Spectra, v. 30, no. 3, p. $989-1005$.

Ancheta, T.D., Darragh, R.B., Stewart, J.P., Seyhan, E., Silva, W.J., Chiou, B.S.-J., Wooddell, K.E., Graves, R.W., Kottke, A.R., Boore, D.M., Kishida, T., and Donahue, J.L., 2014, NGAWest2 database: Earthquake Spectra, v. 30, no. 3, p. 989-1005.

Atkinson, G.M., and Morrison, M., 2009, Observations on regional variability in ground-motion amplitudes for smallto-moderate earthquakes in North America: Bulletin of the Seismological Society of America, v. 99, no. 4, p. 2393-2409.

Baker, J.W., and Cornell, C.A., 2006, Correlation of response spectral values for multicomponent ground motions: Bulletin of the Seismological Society of America, v. 96, p. 215-227.

Baker, J.W., and Jayaram, N., 2008, Correlation of spectral acceleration values from NGA ground motion models: Earthquake Spectra, v. 24, no. 1, p. 299-317.

Baltay, A.S., and Boatwright, J., 2015, Ground-motion observations of the 2014 South Napa earthquake: Seismological Research Letters, v. 86, p. 355-360.

Baumann, C., and Dalguer, L.A., 2014, Evaluating the compatibility of dynamic rupture-based synthetic ground motion with empirical ground-motion prediction equation: Bulletin of the Seismological Society of America, v. 104, no. 2, p. 634-652.

Bommer, J.J., and Scherbaum, F., 2008, The use and misuse of logic trees in probabilistic seismic hazard analysis: Earthquake Spectra, v. 24, no. 4, p. 997-1009.

Boore, M.D., Stewart, J.P., Seyhan, E., and Atkinson, G.M., 2014, NGA-West2 Equations for Predicting PGA, PGV, and 5 percent Damped PSA for Shallow Crustal Earthquakes: Earthquake Spectra, v. 30, no. 3, p. 1057-1085.

Boore, D.M., Watson-Lamprey, J., and Abrahamson, N.A., 2006, Orientation-independent measures of ground motion: Bulletin of the Seismological Society of America, v. 96, p. 1502-1511. 
Bozorgnia, Y., Abrahamson, N.A., Al Atik, L., Ancheta, T.D., Atkinson, G.M., Baker, J.W., Baltay, A., Boore, D.M., Campbell, K.W., Chiou, B.S.-J., Darragh, R., Day, S., Donahue, J., Graves, R.W., Gregor, N., Hanks, T., Idriss, I.M., Kamai, R., Kishida, T., Kottke, A., Mahin, S.A., Rezaeian, S., Rowshandel, B., Seyhan, E., Shahi, S., Shantz, T., Silva, W., Spudich, P., Stewart, J.P., Watson-Lamprey, J., Wooddell, K., and Youngs, R., 2014, NGA-West2 research project: Earthquake Spectra, v. 30, no. 3, p. 973-987.

Cairns, A.J.G., 2000, A Discussion of Parameter and Model Uncertainty in Insurance: Insurance Mathematics and Economics, v. 27, no. 3, p. 313-330.

Campbell, K.W., 2016, Comprehensive Comparison among the Campbell-Bozorgnia NGA-West2 GMPE and Three GMPEs from Europe and the Middle East: Bulletin of the Seismological Society of America, v. 106, no. 5, p. 20812103.

Campbell, K.W., and Bozorgnia, Y., 2014, NGA-West2 Ground Motion Model for the Average Horizontal Components of PGA, PGV, and 5 percent-Damped Linear Acceleration Response Spectra: Earthquake Spectra, v. 30, no. 3, p. 1087-1115.

Chapman, M.C., and Godbee, R.W., 2012, Modeling geometrical spreading and the relative amplitudes of vertical and horizontal high-frequency ground motions in eastern North America: Bulletin of the Seismological Society of America, v. 102, no. 5, p. 1957-1975.

Chiou, B., Darragh, R., Gregor, N., and Silva, W., 2008, NGA project strong-motion database: Earthquake Spectra, v. 24, no. 1, p. $23-44$.

Chiou, B., and Youngs, R.R., 2014, Update of the Chiou and Youngs NGA Model for the Average Horizontal Component of Peak Ground Motion and Response Spectra: Earthquake Spectra, v. 30, no. 3, p. 1117-1153.

Chiou, B., Youngs, R.R., Abrahamson, N., and Addo, K., 2010, Ground-motion attenuation model for small-to-moderate shallow crustal earthquakes in California and its implications on regionalization of ground-motion prediction models: Earthquake Spectra, v. 26, no. 4, p. 907-926.

Erickson, D., McNamara, D.E., and Benz, H.M., 2004, Frequency dependent $\mathrm{Lg} \mathrm{Q}$ within the continental United States: Bulletin of the Seismological Society of America, v. 94 , no. 5 , p. 1630-1643.

Farhadi, A., Pezeshk, S., and Khoshnevis, N., 2018, Assessing the Applicability of Ground-Motion Models for Induced Seismicity Application in Central and Eastern North America: Bulletin of the Seismological Society of America, 108, no. 4, p. 2265-2277.
Ford, S.R., Dreger, D.S., Mayeda, K., Walter, W.R., Malagnini, L., and Phillips, W.S., 2008, Regional attenuation in northern California-A comparison of five 1D Q methods: Bulletin of the Seismological Society of America, v. 98, p. 2033-2046.

Graizer, V., and Kalkan, E., 2007, Ground-motion attenuation model for peak horizontal acceleration from shallow crustal earthquakes: Earthquake Spectra, v. 23, no. 3, p. 585-613.

Graizer, V., and Kalkan, E., 2009, Prediction of response spectral acceleration ordinates based on PGA attenuation: Earthquake Spectra, v. 25, no. 1, p. 39-69.

Graizer, V., and Kalkan, E., 2015, Update of the GraizerKalkan Ground-Motion Prediction Equations for Shallow Crustal Continental Earthquakes: U.S. Geological Survey Open-File Report 2015-1009, 98 p., https://doi.org/10.3133/ ofr20151009.

Graizer, V., and Kalkan, E., 2016, Summary of GK15 GroundMotion Prediction Equation for Predicting PGA and 5 percent-damped SA from Shallow Crustal Continental Earthquakes: Bulletin of the Seismological Society of America, v. 106, no. 2, p. 687-707.

Gregor, N., Abrahamson, N.A., Atkinson, G.M., Boore, D.M., Bozorgnia, Y., Campbell, K.W., Chiou, B.S.-J., Idriss, I.M., Kamai, R., Seyhan, E., Silva, W., Stewart, J.P., and Youngs, R., 2014, Comparison of NGA-West2 GMPEs: Earthquake Spectra, v. 30, no. 3, p. 1179-18.

Idriss, I.M., 2014, An NGA-West2 Empirical Model for Estimating the Horizontal Spectral Values Generated by Shallow Crustal Earthquakes: Earthquake Spectra, v. 30, no. 3, p. 1155-1177.

Jeffreys, H., 1961, Theory of Probability (3rd ed.): Oxford, Oxford University Press, 200 p.

Joyner, W.B., and Boore, D.M., 1993, Methods for regression analysis of strong-motion data: Bulletin of the Seismological Society of America, v. 83, p. 469-487.

Kamai, R., Abrahamson, N.A., and Silva, W.J., 2014, Nonlinear horizontal site amplification for constraining the NGA-West2 GMPEs: Earthquake Spectra, v. 30, no. 3, p. 1223-1240.

Li, Y.G., and Vidale, J.E., 1996, Low-velocity fault-zone guided waves - Numerical investigations of trapping efficiency: Bulletin of the Seismological Society of America, v. 86, p. 371-378.

Mak, S., Clements, R.A., and Schorlemmer, D., 2017, Empirical evaluation of hierarchical ground-motion models - Score uncertainty and model weighting: Bulletin of the Seismological Society of America, v. 107, no. 2, p. 949-965. 
Mitchell, B.J., and Hwang, H.J., 1987, Effect of low Q sediments and Crustal Q on Lg attenuation in the United States: Bulletin of the Seismological Society of America, v. 77 , no. 4 , p. $1197-1210$.

Petersen, M.D., Moschetti, M.P., Powers, P.M., Mueller, C.S., Haller, K.M., Frankel, A.D., Zeng, Y., Rezaeian, S., Harmsen, S.C., Boyd, O.S., Field, N., Chen, R., Rukstales, K.S., Luco, N., Wheeler, R.L., Williams, R.A., and Olsen, A.H., 2014, Documentation for the 2014 update of the United States national seismic hazard maps: U.S. Geological Survey OpenFile Report 2014-1091, 243 p.

Sadigh, K., Chang, C.Y., Egan, J.A., Makdisi, F., and Youngs, R.R., 1997, Attenuation relationships for shallow crustal earthquakes based on California strong motion data: Seismological Research Letters, v. 68, no. 1, p. 180-189.

Seyhan, E., and Stewart, J.P., 2014, Semi-empirical nonlinear site amplification from NGA-West2 data and simulations: Earthquake Spectra, v. 30, no. 3, p. 1241-1256.

Singh, S., and Herrmann, R.B., 1983, Regionalization of crustal coda Q in the continental United States: Journal of Geophysical Research, v. 88, no. B1, p. 527-538.
Spudich, P., Joyner, W.B., Lindh, A.G., Boore, D.M., Margaris, B.M., and Fletcher, J.B., 1999, SEA99-A revised ground motion prediction relation for use in extensional tectonic regimes: Bulletin of the Seismological Society of America, v. 89, p. 1156-1170.

Thorburn, W.M., 1915, Occam's razor: Mind, v. XXIV, p. $287-288$.

Vandekerckhove, J., Matzke, D., and Wagenmakers, E.J., 2015, Model comparison and the principle of parsimony in Busemeyer, J., Townsend, J., Wang, Z.J., and Eidels, A., eds., Oxford handbook of computational and mathematical psychology: Oxford, Oxford University Press, p. 300-319.

Van Houtte, C., Bannister, C., Holden, C., Bourguignon, S., and McVerry, G., 2017, The New Zealand strong motion database: Bulletin of the New Zealand Society for Earthquake Engineering, v. 50, no. 1, p. 1-20.

Zafarani, H., and Farhadi, A., 2017, Testing ground-motion prediction equations against small-to- moderate magnitude data in Iran: Bulletin of the Seismological Society of America, v. 107, p. 912-933. 
Menlo Park Publishing Service Center, California Manuscript approved March 13, 2020

Edited by Monica Erdman

Layout by Cory Hurd 
